\title{
SOBRE HERRERA «EL VIEJO»
}

\author{
POR \\ ALFONSO E. PÉREZ SÁNCHEZ \\ Universidad Complutense \\ BENITO NAVARRETE PRIETO \\ Universidad de Valencia
}

In this article we introduce to the public knowledge a new collection of works by Francisco de Herrera, el Viejo, unknown until now, that enlarge considerably his catalogue. Within them we point out a set of architectural preparatory drawings for the gypsum-klin (yeserías) of the Convento de Santa Buenaventura in Sevilla, and also the discovery one architect's notebook that shows an important series of Sevillian designs. At the same time, we remark different aspects of his formation as painter, mentioning the possible influence of Pablo de Céspedes and some flemish masters like Martin de Vos, and we allude to the contacts, not referred until the present day, with Ribera and the young Alonso Cano.

We also bring up some information about certain lost works, not considered in previous studies, and some problematic attributions.

Desde la publicación de la amplia monografía que le dedicó en 1978 Antonio Martínez Ripoll ${ }^{1}$ son escasas las aportaciones a la vida y a la obra del pintor sevillano Francisco de Herrera el Viejo, aunque algunos lienzos nuevos se han podido añadir a su catálogo ${ }^{2}$ y ciertas precisiones respecto a procedencias y vicisitudes de sus obras han enriquecido nuestro conocimiento.

Pero sigue todavía siendo relativamente escasa la producción identificada de este artista que conoció en su tiempo éxito y prestigio singulares, pero que mantiene aun poco definidos los ingredientes de su personal estilo, cuya evolución, aunque trazada en sus líneas generales en la citada monografía, necesita todavía de precisiones y matices que sólo harán posibles el descubrimiento de nuevas obras.

\footnotetext{
1 Antonio Martínez Ripoll, Francisco de Herrera, «el Viejo», Sevilla, 1978.

2 María Luisa Cano Navas, dio a conocer, en 1980 (Congreso Español de Historia del Arte) el retablo de la Anunciación del Convento sevillano de las Teresas, documentado en 1627, publicándolo en la Revista de Arte Sevillano, Junio 1983, n. ${ }^{\circ}$ 3 pp. 69-71 («Nueva aportación a la obra de Francisco de Herrera el Viejo. Los cuadros del convento de San José del Carmen en Sevilla") y recogido luego en su libro El Convento de San José del Carmen, Sevilla, 1984. También en 1980, E. Valdivieso y J. M. Serrera (El Hospital de la Caridad de Sevilla, Sevilla, 1980, p. 43), dieron a conocer la Visión de Constantino, superviviente de la Serie de la Cofradía de la Vera Cruz. Los mismos autores (La época de Murillo, Catálogo de la Exposición, Sevilla, 1982, n. ${ }^{\circ}$ 151), reprodujeron la Flagelación de Cristo de La Hermandad Sacramental de San Bernardo de Sevilla, hasta entonces desconocida. En 1986 el Museo de Castres adquirió un notable lienzo de la Multiplicación de los panes y los peces, aparecido en una venta pública en Burdeos, y en 1987 Nina Ayala Mallory («Una obra desconocida de Francisco de Herrera «el Viejo», Archivo Español de Arte, 1987, pp. 357-364), publicó un importante lienzo, El rescate de San Luis, firmado en 1614. En el Catálogo de la Exposición Tres siglos de dibujo sevillano, Sevilla, 1985, por último, dimos a conocer la existencia de una serie de Apóstoles del Museo de Córdoba, de 1a que se hablará más adelante.
} 
A ir colmando esos vacíos y a enriquecer su catálogo con nuevas obras y nuevas observaciones responde cuanto aquí presentamos.

Novedad importante constituye la identificación de unos dibujos que son, sin lugar a dudas, preparatorios para la decoración del sevillano Colegio de San Buenaventura. Como es sabido ${ }^{3}$ el 4 de mayo de 1626, los maestros de obras Juan de Velasco y Juan de Segarra se comprometen a realizar toda la obra de adorno "de yesería, talla y escultura", que había de "quedar e hacerse a gusto y satisfacción del dicho Francisco de Herrera y por las trazas y dibujos que ha dado y diere».

Los dibujos ahora identificados se conservan en un volumen misceláneo, que hubo de pertenecer sin duda a un arquitecto, probablemente sevillano, de mediados del siglo xvir ${ }^{4}$ y reúne, junto a páginas de la edición de Vignola de 1562(?) un conjunto interesante de dibujos de retablos; grabados de Vredeman de Vries, y diversas estampas de monumentos arquitectónicos italianos además de dos grabados del propio Herrera: la portada de los Comentarios a la Suma Teológica de Santo Tomas, de 1623, y la rarísima estampa del Patronato de la Orden Trinitaria, de 1627 de la que hasta el presente sólo se conocía el ejemplar de la Biblioteca Nacional ${ }^{5}$, así como una prueba de estado de la portada del libro Novus Index Librorum Prohibitorum del Cardenal Zapata, que dibujó Juan de Herrera, hermano del pintor, antes de incorporar el texto y las armas del cardenal.

Los dibujos de Herrera son, en primer lugar, el alzado de uno de los tramos laterales de la nave del Colegio, comprendido entre dos pilastras estriadas de orden dórico romano, con un sencillo arco sobre el que van unos marcos casi cuadrados, para albergar lienzos (Fig. 1).

En la clave del arco va una cabeza de querubín y otra en la parte superior del recuadro; éste, en sus laterales, se decora con motivos de pergaminos de tradición manierista. Sobre las pilastras va un entablamento cuyo friso se decora con cartelas con dos cabezas de querubines sobre los capiteles y otra cartela de pergaminos sobre el eje del hueco, unidas entre sí por guirnaldas de frutas y una cornisa de prietos dentellones.

El dibujo, de dimensiones $390 \times 245$ milímetros, lleva pitipié en palmos, y está cuidadosamente delineado con pluma y ligerísima aguada sepia.

Todo se corresponde con lo realizado en la iglesia de San Buenaventura, con algunas variantes de detalles (las cartelas sobre los capiteles no llevan cabezas de querubines; las guirnaldas son algo más largas y los dentellones de la cornisa se distancian más, con un ritmo diferente) y no parece caber duda respecto a que nos hallamos ante un dibujo arquitectónico del maestro, precisamente el que habría de servir de marco a los hermosos lienzos de su mano y a los compañeros, de Zurbarán ${ }^{6}$ (Fig. 2 y 2 bis).

El segundo dibujo, de forma irregular y dimensiones máximas de $365 \times 305$, también en tinta y ligera aguada sepia, se refiere a la decoración de la cúpula de la misma iglesia, y ofrece, con refinada perfección, el despiece de los dos tipos de compartimentos que la decoran: la mitad de uno de los de forma trapezoidal y uno de los de forma aovada, detallando la decoración que va entre ellos, con cabezas de querubines y guirnaldas de frutas. Todo coincide con lo realizado, de modo fidelísimo ${ }^{7}$ (Fig. 3 y 4 ).

Ambos dibujos son de una refinada calidad y su peculiar técnica permite atribuir a Herrera un tercer dibujo, del mismo volumen, de dimensiones $350 \times 240$, también a pluma y aguada sepia,

\footnotetext{
3 A. Martínez Ripoll, La iglesia del Colegio de San Buenaventura, Sevilla, 1976, pp. 13 ss. y ss.

4 El volumen, cuya existencia nos ha sido amablemente señalada por Fernando Benito, se guarda en la Biblioteca del Colegio de Arquitectos de Valencia (sig. R. 103) y esperamos poder publicar, en breve, un estudio detallado de su interesante contenido.

5 Véase A. Martínez Rípoll, 1978, p. 247 n. ${ }^{\circ}$ G3 y G4, figs. 6 y 7.

6 A. Martínez Ripoll, 1978, p. 139, n. ${ }^{\circ}$ A5, fig. 10.

7 A. Martínez Ripoll, 1978, p. 139, n. ${ }^{\circ}$ A5, figs. 5-8.
} 

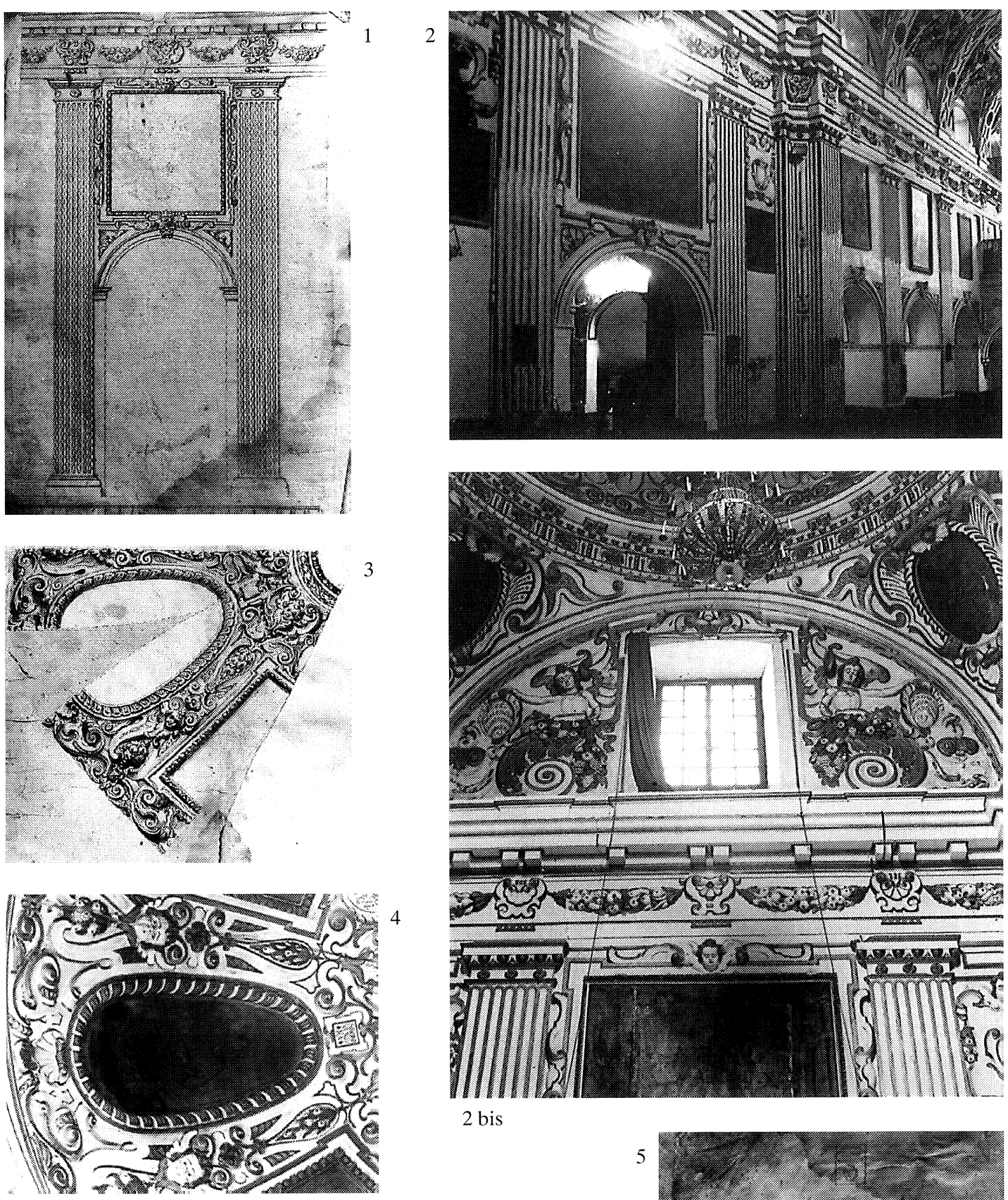

2 bis

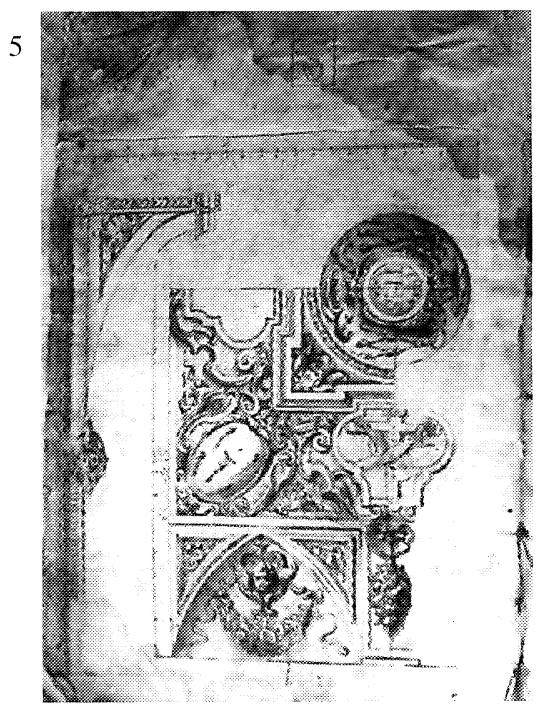

Fig. 1. Herrera «el Viejo», Dibujo arquitectónico: Valencia, Biblioteca del Colegio de Arquitectos.

Fig. 2. Detalle de la nave del Colegio de San Buenaventura, Sevilla. Fig. 2 bis. Nave del Colegio de San Buenaventura.

Fig. 3. Herrera «el Viejo», Dibujo arquitectónico. Valencia, Biblioteca del Colegio de Arquitectos.

Fig. 4. Detalle de la Cúpula del Colegio de San Buenaventura.

Fig. 5. Herrera «el Viejo", Dibujo arquitectónico. Valencia, Biblioteca del Colegio de Arquitectos. 
preparatorio sin duda para una bóveda de templo franciscano, pues lleva el escudo de las cinco llagas, y el emblema de los brazos de Cristo y San Francisco cruzados sobre la cruz (Fig. 5).

Muestra también un escudo cardenalicio con el. monograma de Jesús, y la fecha de 1626 que es, como puede verse, precisamente la de realización de la obra de San Buenaventura.

Este tercer dibujo, idéntico de técnica y motivos (véanse especialmente las cabecitas de querubines, las guirnaldas de frutas y el tipo de tarjas o cartelas de pergaminos), es posible que se proyectase para alguna otra dependencia del mismo Colegio que, o no llego a construirse o no ha llegado hasta nosotros.

Los motivos franciscanos y el capelo cardenalicio con las armas de Jesús, hacen pensar precisamente en San Buenaventura, titular del colegio, tal como confirma además la citada fecha de 1626.

Otros trabajos de Herrera para conventos franciscanos, como el convento de Santa Inés, en cuya decoración pintada aparece también el monograma de Jesús y los brazos cruzados sobre la cruz, son, si efectivamente fuesen suyos, de época algo más tardía ${ }^{8}$.

El severo alzado de los muros, de tipo vignolesco, y los motivos decorativos para las bóvedas, tan dentro de la tradición manierista de un Giacomo della Porta, proporcionan una mejor visión del modo en que nuestro artista encara la decoracion arquitectónica, muy dentro de lo habitual en la Sevilla de su tiempo, y en abierto contraste con la severidad escurialense que en las mismas fechas dominaba en el medio castellano.

En un momento relativamente temprano en su producción y desde luego en la década de los 20 hay que situar tres lienzos, dos de ellos en grisalla, conservados en el Museo de Bellas Artes de Sevilla, que salvo uno de ellos, no han sido hasta ahora puestos en relación directa con Herrera, cuyos tipos y carácter presentan de modo inconfundible.

Se trata de tres figuras de Santos jesuitas, arrodillados con acompañamiento de gloria. Uno de ellos, el de menores dimensiones $(2,19 \times 1,50)$ y pintado en la gama cálidad de castaños dorados sobre los que destaca la severa mancha negra del hábito, representa a San Ignacio, perfectamente reconocible por su inconfundible rostro, recibiendo de los ángeles el emblema de la Compañía, con la Trinidad en gloria en la parte superior (Fig. 8).

No se sabe de donde procede, pero es lógico pensar que de una casa jesuita, probablemente 1a misma Casa Profesa de donde se supone proceden los otros dos. Este se atribuía a Roelas, con un punto interrogativo, y así se recoge en el Catálogo de 1896 y en el de Gestoso de 1912. Hernández Díaz, en 1967, eliminó el interrogante, y E. Valdivieso señalo ya que "su estilo es más próximo al que creara Herrera el Viejo", rechazando decididamente la atribución a Roelas. En el inventario de 1990 figura como anónimo ${ }^{9}$ pero en 1991 el mismo Valdivieso lo reproduce ya como obra de Herrera.

De las dos grisallas, de dimensiones algo mayores $(2,27 \times 1,76)$, una de ellas repite la composición del lienzo anterior, aunque con suficientes variantes para hacer de él una composición nueva. La otra representa a San Francisco Javier (que se reconoce por su lema SATIS EST NON SATIS, y por la presencia de un navío en naufragio, que alude sin duda a las incidencias de su predicación en Oriente), acompañado, de un ángel que porta un gran pergamino con la inscripción: «Tribulatio, Angustia, Fames, Nuditas, Periculum, Persecutio, Glaudius».

El primer lienzo es, seguramente, cuadro de altar, pero las grisallas debieron formar parte de un aparato efímero, en ocasión de fiestas jesuíticas. Viene a la memoria la canonización, en 1622, de los dos santos representados, San Ignacio y San Francisco Javier y cabría pensar que los

\footnotetext{
8 A. Martínez Ripoll, 1978, pp. 153-155, figs. 44, 47 y 53.

9 Catálogo del Museo de Sevilla, 1897, n. ${ }^{\circ} 1$ (Roelas ?).- J. Gestoso, Catálogo de las pinturas y esculturas del Museo Provincial de Sevilla, 1912, n. ${ }^{\circ}$ 147.-J. Hernández Díaz, Museo Provincial de Bellas Artes de Sevilla, 1967, n. ${ }^{\circ}$ 98.-E. Valdivieso, Juan de Roelas, Sevilla, 1978, p. 119.-Rocío Izquierdo y Valme Muñoz, Museo de Bellas Artes. Inventario de Pintura, Sevilla, 1990, p. 59 (n. inventario 280). E. Valdivieso en Museo de Bellas Artes de Sevilla. Sevilla 1991, p. 143 , fig. 150.
} 
lienzos se pintaran en aquella ocasión. Quizás el tratarse de obras de ejecución apresurada y quizás incorrecta, que se aleja un tanto de las obras más acabadas y expresivas del pintor, ha dificultado su identificación. No deja de sorprender un tanto, que en los inventarios y catálogos del Museo se hayan venido atribuyendo a Valdés Leal ${ }^{10}$ (Figs. 6 y 7).

Carecemos de noticias documentales de Herrera en el año 1622 en que hubieron de celebrarse fiestas por la canonización de los santos jesuitas, pero nos constan sus relaciones con el mundo de la Compañía de Jesús al menos desde 1610 en que grabó la portada del libro de la Relación de la fiesta que se hizo en Sevilla a la Beatificación del Glorioso San Ignacio fundador de la Compañía de Jesús. En 1623 volvemos a encontrarle grabando la portada de otra obra de un jesuita, los Commentarii in Summan Theologiae S. Thomae, del padre Jacobo Granado del Colegio de San Hermenegildo de Sevilla,precisamente el colegio teológico donde Palomino sitúa el legendario asilo del pintor, acusado de monedero falso, y para el cual pintó una de sus obras maestras, la Apoteosis de San Hermenegildo, en fecha que ignoramos, pero que no estará muy lejana de 1620-25.

Otro testimonio de su relación con los jesuitas, es el gran lienzo de San Francisco Javier en éxtasis, de la Universidad sevillana que es, además, la obra que más cerca está de estas grisallas hasta hacer pensar en fecha próxima y quien sabe si, incluso, en una misma ocasión.

Quizás el hecho de que hasta fechas relativamente recientes se haya dudado de la paternidad del gran lienzo de la Universidad ${ }^{11}$ haya condicionado también el silencio sobre éstos, tan próximos. La restauración de aquél no deja ya lugar a dudas, y estos lienzos han de incorporarse también al catálogo del pintor, aunque quizás, en las grisallas y por su carácter efímero, haya que pensar en la colaboración de oficiales y quien sabe si de su hermano Juan de Herrera, pintor también aunque sólo conocido por los documentos y su obra de iluminador ${ }^{12}$.

Los modelos de los ángeles niños, de tan peculiar estructura facial, anchos de rostro, con sotabarba y cabellos de rizos tan enérgicamente trazados, se encuentran idénticos en otras obras de la década de los veinte, como el citado San Francisco Javier de la Universidad o la Inmaculada del Museo de Sevilla -que también se atribuyo a Roelas, como el San Ignacio que presentamos-, y los plegados abundosos en quebraduras, son los mismos -aunque la técnica de la grisalla los endurezca un tanto-, que se encuentran en la citada Inmaculada e incluso en los lienzos de la Serie de San Buenaventura.

Obra de suma importancia, desconocida hasta ahora y de indudable adscripción al maestro, es una gran Santa Cena de colección particular malagueña, que fue fotografiada en 1976, pero que ha permanecido inédita hasta hoy (Figs. 9-11).

De amplias dimensiones $(2,48 \times 2,35)$, estuvo en su origen rematada en medio punto, $y$ fue luego, sin duda en el pasado siglo, convertida al formato cuadrado.

Respondiendo al tipo iconográfico de la Cena eucarística, presenta a Cristo en, el momento de bendecir el pan con los ojos alzados al cielo y rodearlo de las expresiones apasionadas de los Apóstoles. Judas, en primer término, vuelve la cabeza al espectador apartándose de la escena con gesto hosco.

10 Los catálogos antiguos los atribuían a Valdés Leal desde el de 1896 . Gestoso en 1912 (n. ${ }^{\circ} 169$ y 170 ), mantiene la atribución y los incluye con los restantes lienzos jesuitas de Valdés bien documentados en 1674-76. Beruete en 1911 (Valdés Leal, 1911, p. 100), no se pronuncia pero subraya ya que «no son obras típicas ni interesantes». Hernández Díaz (1967, p. 53) los sigue considerando de Valdés, siguiendo a Gestoso, y Kinkead (Valdés Leal, 1978, p. 446), apunta la hipótesis de que están dibujados por Valdés y pintados por su discípulo Juan Antonio Navarro. E. Valdivieso, por último (Valdés Leal, Sevilla, 1988, p. 286), rechaza decididamente la vieja atribución sin proponer otra. En el Inventario de 1990 (R. Izquierdo y V. Muñoz, p. 51), se recogen como anónimos bajo los números de inventario 217 y 203 respectivamente.

11 Thacher (1937, pp. 369-370) y Hernández Díaz (La Universidad Hispalense y sus obras de Arte, 1942, p. 40), lo consideraron "afín a su taller" Martínez Ripoll, ob. cit., 1978, p. 145, n. ${ }^{\circ}$ P15, lo considera ya obra segura y significativa del maestro.

12 Teresa Laguna Paúl, «Juan de Herrera y las reglas de la Cofradía de la Vera Cruz. Una contribución al estudio de la miniatura sevillana del siglo xviı" Laboratorio de Arte. Sevilla, 1995, pp. 127-156. 


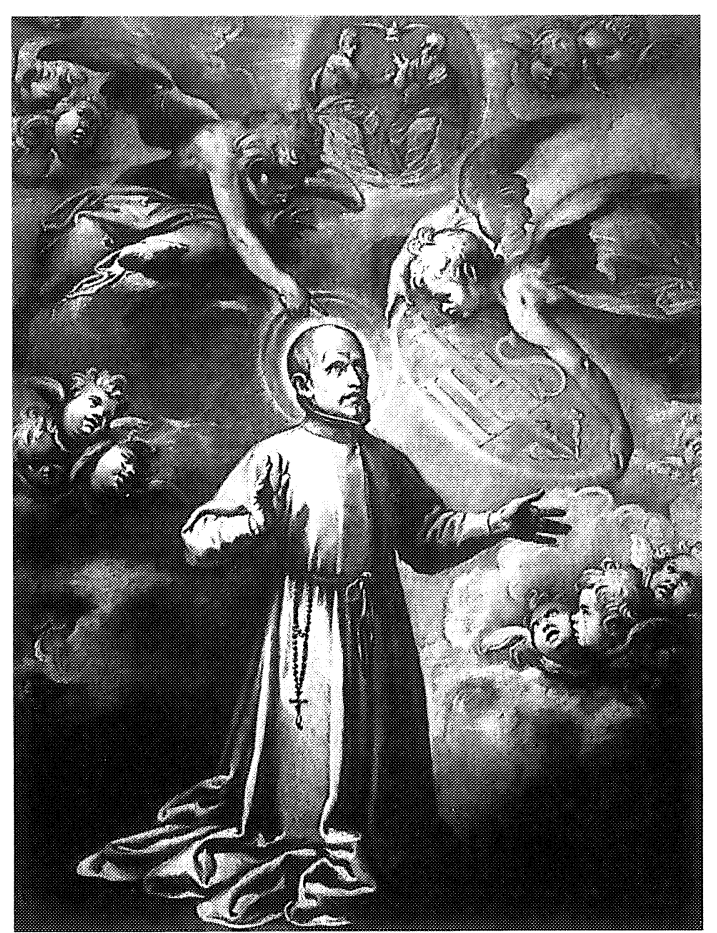

6

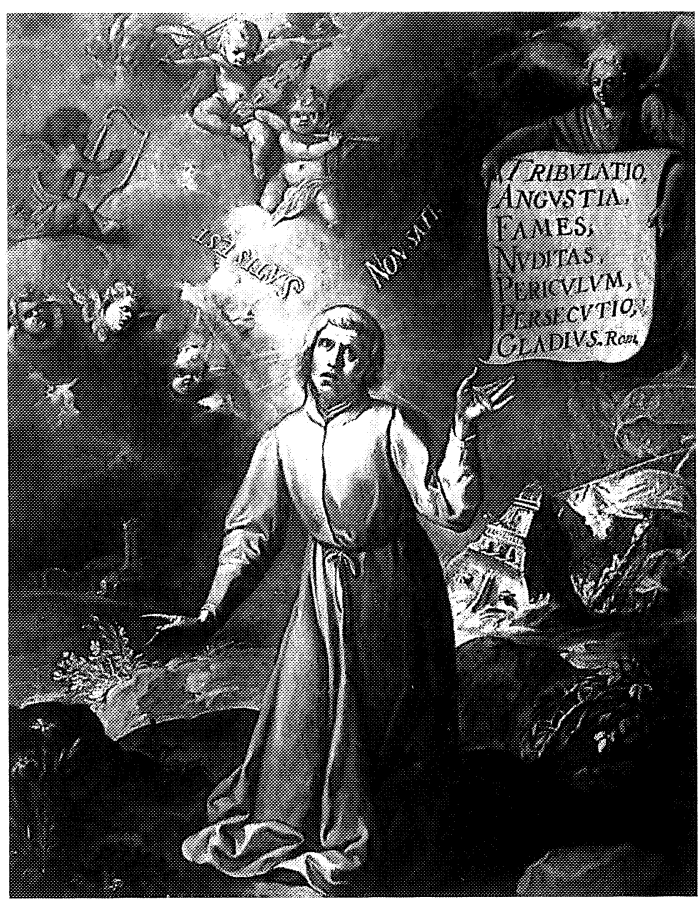

7
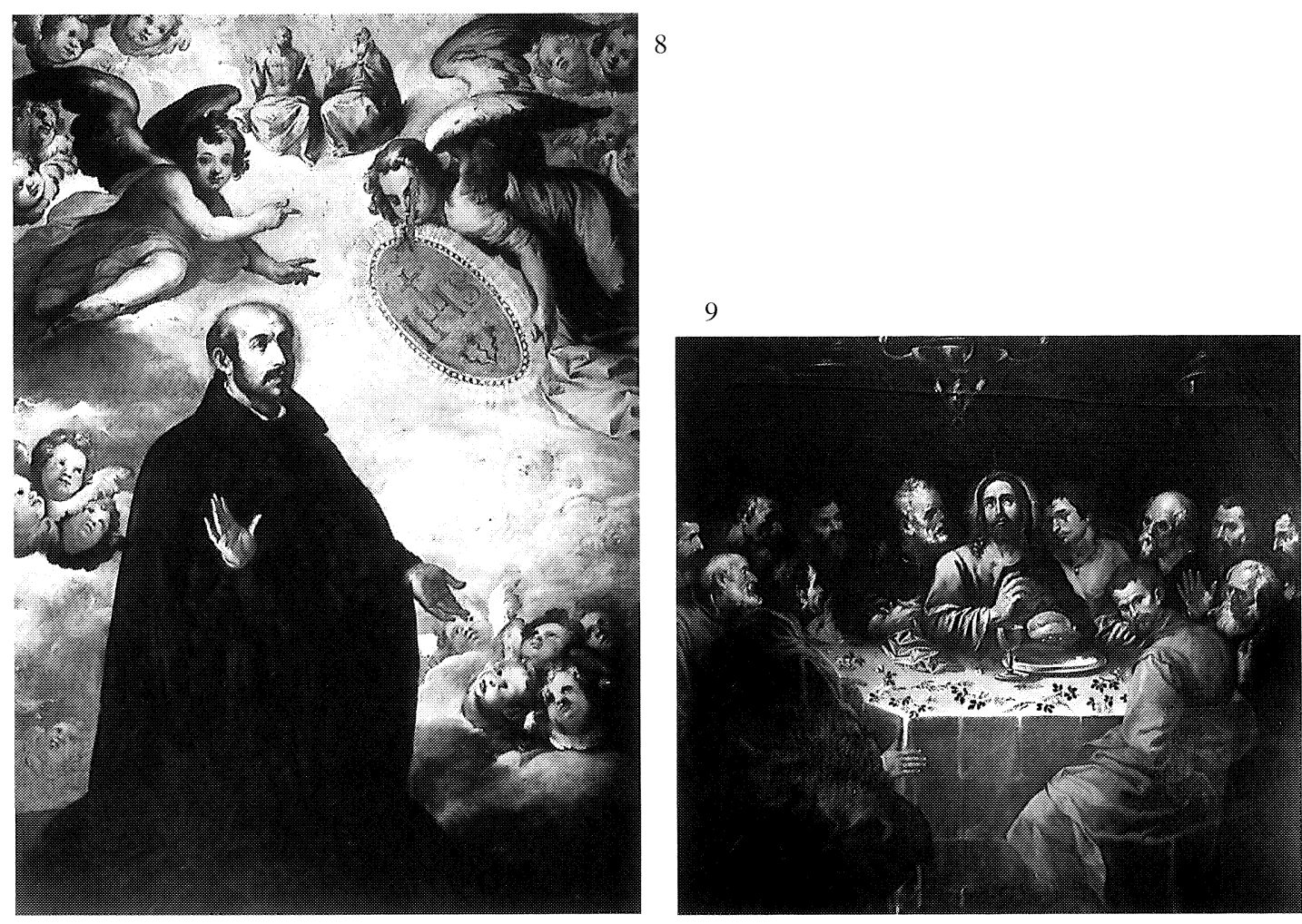

Fig. 6. Herrera «el Viejo», San Ignacio de Loyola. Sevilla, Museo de Bellas Artes.

Fig. 7. Herrera "el Viejo", San Francisco Javier. Sevilla, Museo de Bellas Artes.

Fig. 8. Herrera "el Viejo», San Ignacio de Loyola. Sevilla, Museo de Bellas Artes.

Fig. 9. Herrera "el Viejo", Santa Cena. Colección Particular. 


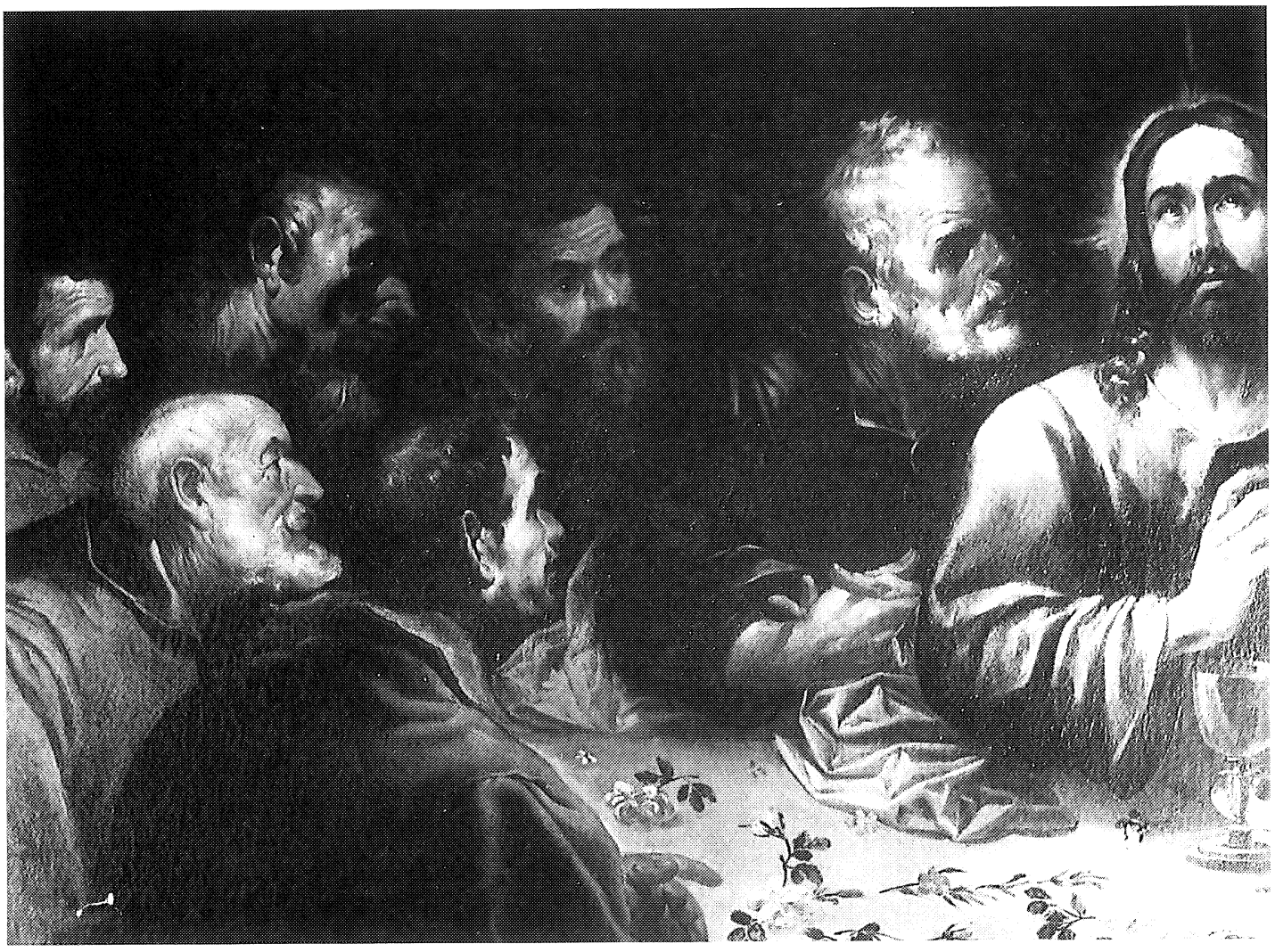

Fig. 10. Herrera «el Viejo», Santa Cena, detalle. Colección particular.

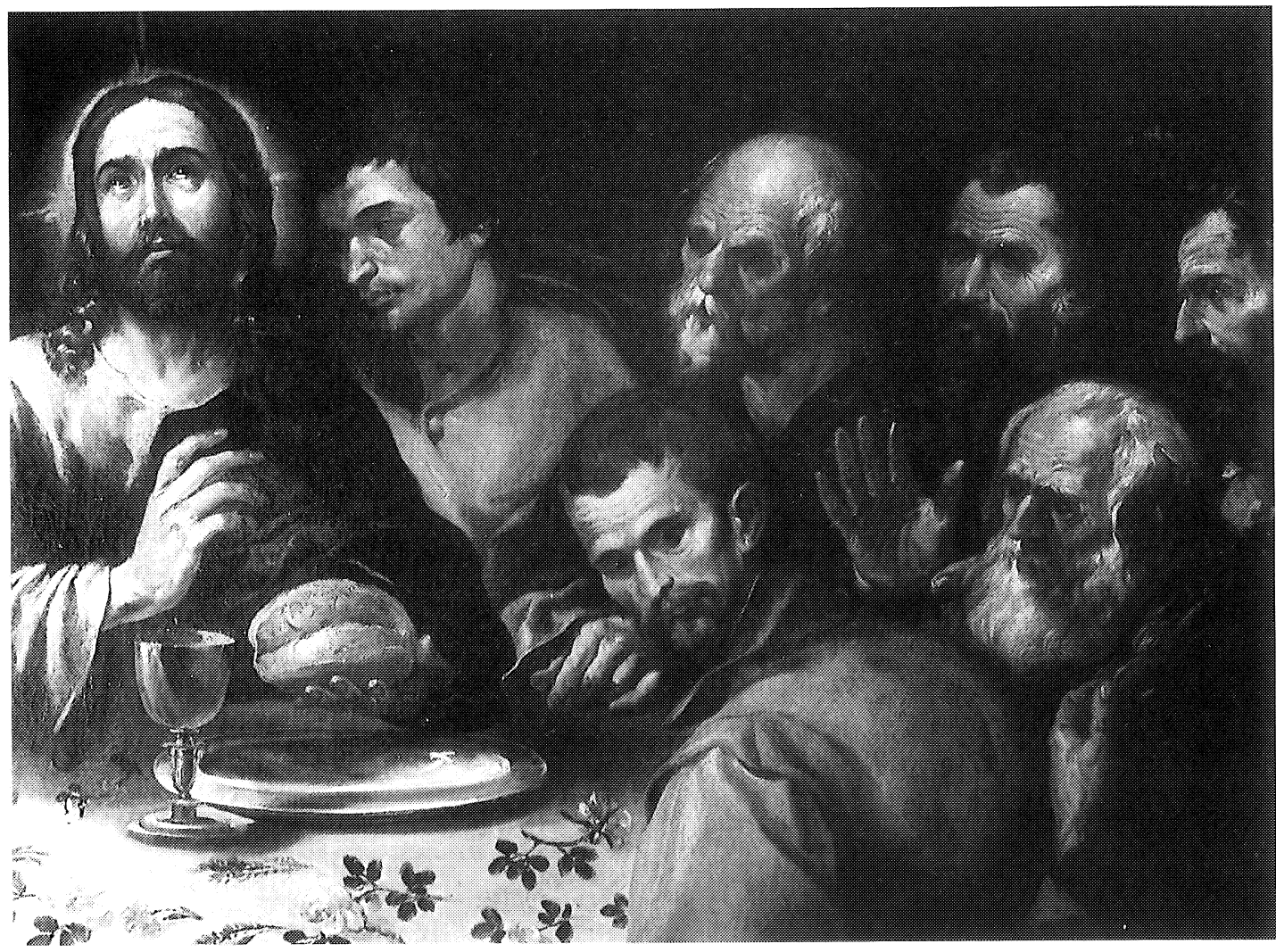

Fig. 11. Herrera «el Viejo», Santa Cena, detalle. Colección particular. 
Sobre la mesa, de formato cuadrado, sólo se ve el cáliz, una amplia bandeja metálica -la patena litúrgica- bajo la mano que sostiene el pan, y una serie de florecillas dispersas por el mantel. Se ha omitido voluntariamente toda la parafernalia habitual en otras Cenas, interpretadas a modo de bodegón y se busca la concentración máxima en el hecho eucarístico.

La iluminación, de acentuados contrastes, subraya el efecto nocturno, marcado por la rica lámpara de mecheros encendida sobre la cabeza del Salvador, que ilumina las altas basas de la columnata que cierra el espacio donde transcurre la acción.

Los rostros de los personajes y su tratamiento, enérgico y sintético, son bien característicos del pintor y aparecen con frecuencia en sus composiciones. El del Cristo es, especialmente, idéntico al del Milagro de los Panes y los Peces del Palacio Arzobispal de Madrid y su mano derecha repite, fielmente, el gesto de bendición que allí se muestra.

Los Apóstoles son todos ellos modelos repetidos en sus lienzos de composición compleja e incluso en sus dibujos. Especialmente próximos son los rostros de los Bienaventurados de la parte superior del Juicio Final de la Iglesia sevillana de San Bernardo, que ofrecen un amplio y variado repertorio de modelos y actitudes.

Los plegados amplios, que llenan toda la parte delantera del lienzo, en dos grandes masas de tonalidades pardas, son también habituales en el artista que recurre a ese mismo recurso un tanto desmañado, en otras composiciones suyas. Piénsese, por ejemplo, en el San Buenaventura niño, curado por San Francisco del Louvre, o en el lienzo compañero de la Aparición de Santa Catalina a la familia de San Buenaventura de la Bob Jones Uníversity. Los ampulosos pliegues, de múltiples quebraduras, subrayadas por la pincelada pastosa y densa, se manifiestan aquí algo contenidos, cerrando la composición al converger en el centro dejando abierto el espacio para la mesa iluminada, en evidente acierto compositivo.

Nada se sabe de la procedencia primera de este importante lienzo. Sus propietarios lo adquirieron en una casa noble de Osuna. Se tiene noticia de varios «lienzos grandes» de Herrera el Viejo, que representaban la Santa Cena. Rematado en medio punto, y con unas dimensiones aproximadas de 2,24 m de base era el lienzo que presidía el altar de la Cofradía del Santísimo Sacramento y Animas del Purgatorio en la iglesia sevillana de San Pedro, contratado en 1619 y concluido, al parecer, en septiembre de 1620, en que Herrera otorgó carta de pago y finiquito ${ }^{13}$. Desaparecido el lienzo seguramente cuando la Guerra de la Independencia, nada se sabe de él, pero es de suponer que su estilo fuese acorde con el de las Animas del Purgatorio de su banco o predela, que afortunadamente sí se conservan y parecen de estilo algo más antiguo que lo que muestra el cuadro que aquí presentamos. No obstante, la semejanza de las dimensiones y el remate en medio punto hacen muy probable que se trate del mismo lienzo.

Otro lienzo del mismo asunto "grande" y con "figuras del natural» se hallaba en el convento sevillano de la Merced Calzada, «casa grande» y era compañero de una Venida del Espíritu Santo de idénticas dimensiones. Constituían ambos los altares colaterales del Noviciado y no hay noticias de ellos posteriores a la Desamortización de $1836^{14}$.

Se ha supuesto que esa Venida del Espiritu Santo pueda ser la que guarda el Museo del Greco de Toledo, fechada en 1617. Si así fuese, esta Santa Cena no puede ser su compañera, pues su estilo, como veremos, es claramente más avanzado.

Aún otro lienzo del mismo asunto se inventarió en 1810 entre los cuadros reunidos en el Alcazar de Sevilla durante la Guerra de la Independencia. Medía $4 \times 3$ varas $(3,35 \times 2,51$ aproximadamente) y, como ha señalado Martínez Ripoll, parecía formar parte de un conjunto de ca-

\footnotetext{
13 Martínez Ripoll, 1978, p. 204, n. ${ }^{\circ}$ P.p.76.

14 Martínez Ripoll, 1978, p. 202, n. ${ }^{\circ}$ P.p.67.
} 
rácter eucarístico franciscano ${ }^{15}$, lo que parece excluir su identificación con el cuadro de la iglesia de San Pedro, ya citado, con el que según Martínez Ripoll cabría ponerlo en relación.

Sus dimensiones son más próximas a las del lienzo presente, pero sorprende que no se haga alusión al formato en medio punto. Por todo ello, creemos que no puede proponerse identificación segura alguna.

En cuanto a la fecha probable para esta nueva composición, ya se ha apuntado su estrecha relación con obras como el .Juicio Final de San Bernardo, los lienzos de la Serie de San Buenaventura, o el Milagro de los Panes y Peces, que se fechan en los momentos de plenitud de su producción, entre 1628-29, fecha de los primeros, y 1640-45, en que se puede situar el último. El estrecho paralelo ya señalado más arriba entre las figuras de Cristo en el lienzo que ahora presentamos y en el del Palacio Arzobispal madrileño, inclina a situarlo más cerca de este último, quizás en torno a 1640. Pero ya se ha dicho que podría ser el lienzo documentado en 1620, lo que obligaría a ver ya consolidado su estilo en fecha muy temprana y a subrayar un carácter conservador y sostenido durante toda su larga etapa sevillana.

Aún cuando la composición se ciñe a un esquema muy habitual desde el siglo xvi, y pueden señalarse antecedentes en estampas del manierismo romano, que conocieron también Ribalta y Carducho, no deja de ser curiosa la semejanza de este lienzo con la Santa Cena de Murillo en la iglesia sevillana de Santa María la Blanca, obra de hacia 1650 según todos los críticos. Rematado también en medio punto, ofrece muchísimos puntos de contacto, desde el gesto del Cristo o la posición y actitud de Judas, hasta la distribución de los puntos de luz y la lámpara que ilumina la escena, desplazada por Murillo a un lateral, como corresponde a una sensibilidad barroca más avanzada. Incluso la disposición de la mesa cuadrada y esquinada, y la mano del apóstol de la izquierda recortándose sobre el mantel, son coincidencias demasiado fieles, que obligan quizás a pensar en que el joven Murillo mirase con atención el cuadro del ya maduro Herrera. No es la primera vez que lo hizo. Baste recordar la serie de San Juan pintada para el convento de San Leandro, también hacia $1650{ }^{16}$.

El Museo de Bellas Artes de Córdoba conserva un Apostolado de figuras de más de medio cuerpo de dimensiones que oscilan entre $1,12 \times 0,89$ y $1,13 \times 90$ que ingresaron en el mismo en 1868 procedentes del Convento de Santa Clara de Priego a raíz de la desamortización decretada por el gobierno revolucionario. Se atribuyeron al cordobés Juan Luis Zambrano y por su mal estado de conservación han pasado inadvertidas hasta fecha bien reciente en que al estudiar los dibujos de Herrera conservados en la Kunsthalle de Hamburgo hemos podido ponerlos en relación con ella y señalarla, para nosotros evidente, atribución al propio Herrera ${ }^{17}$ (Figs. 12-22).

A pesar del penoso estado de conservación que se ha de procurar remediar con restauraciones prudentes, ya en marcha, la atribución no parece ofrecer duda alguna y la citada relación con los dibujos de Hamburgo -que son seguramente un repertorio de rostros y actitudes para ser utilizadas en las ocasiones más diversas- nos dice mucho del modo de trabajar del pintor, que seguramente se hubo de valer de colaboradores que ignoramos para atender la demanda creciente en los momentos de su mayor éxito en la década de los treinta en la que hay, sin duda, que colocar esta serie.

En estrecha relación con ese Apostolado y por lo tanto también con los dibujos de Hamburgo, está una noble figura de Filósofo $(0,75 \times 0,59)$ de la antigua colección florentina Contini Bo-

\footnotetext{
15 Martínez Ripoll, 1978, p. 205, n. ${ }^{\circ}$ P.p.81.

16 A. E. Pérez Sánchez, De pintura y pintores, Madrid, 1993, pp. 133-134, figs. 222-224.

17 A.E. Pérez Sánchez y Benito Navarrete, Tres siglos de dibujo sevillano, Sevilla, 1995, pp. 121-135. Agradecemos a Fuensanta García de la Torre, Directora del Museo de Córdoba las informaciones relativas a 1a procedencia de los lienzos y las facilidades para obtener las fotografías. Sólo dos de los lienzos - los de mejor conservación- habían sido fotografiados por el Archivo Más (n. ${ }^{\circ}$ C 98547 y C98548), siempre con atribución a Zambrano.
} 


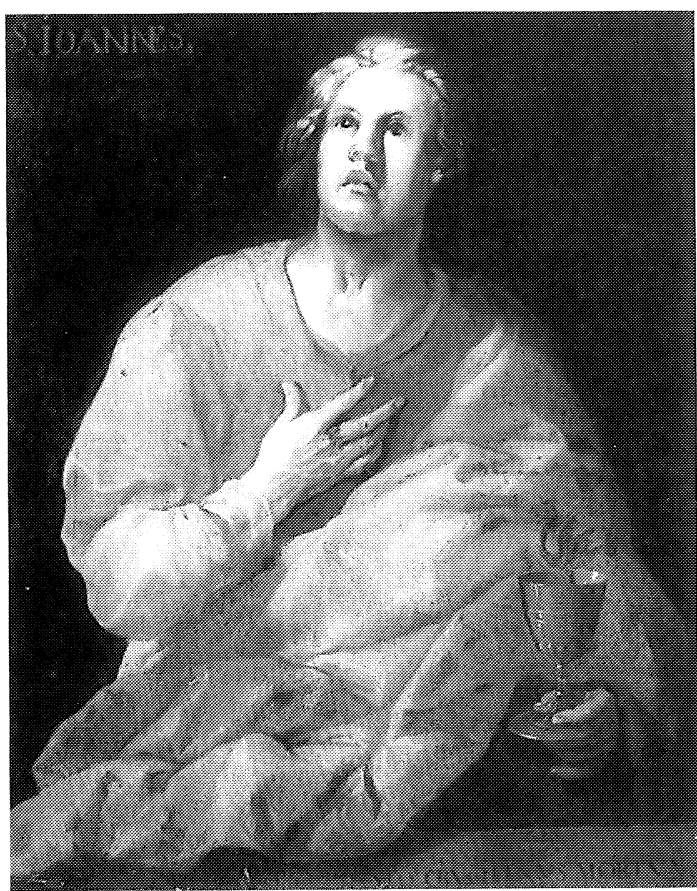

12

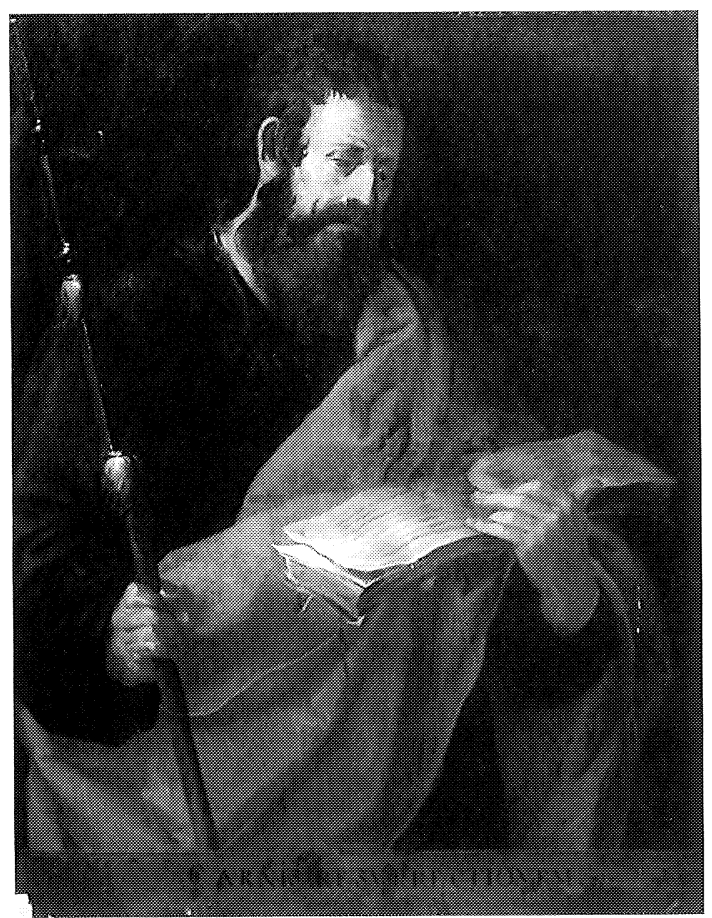

14

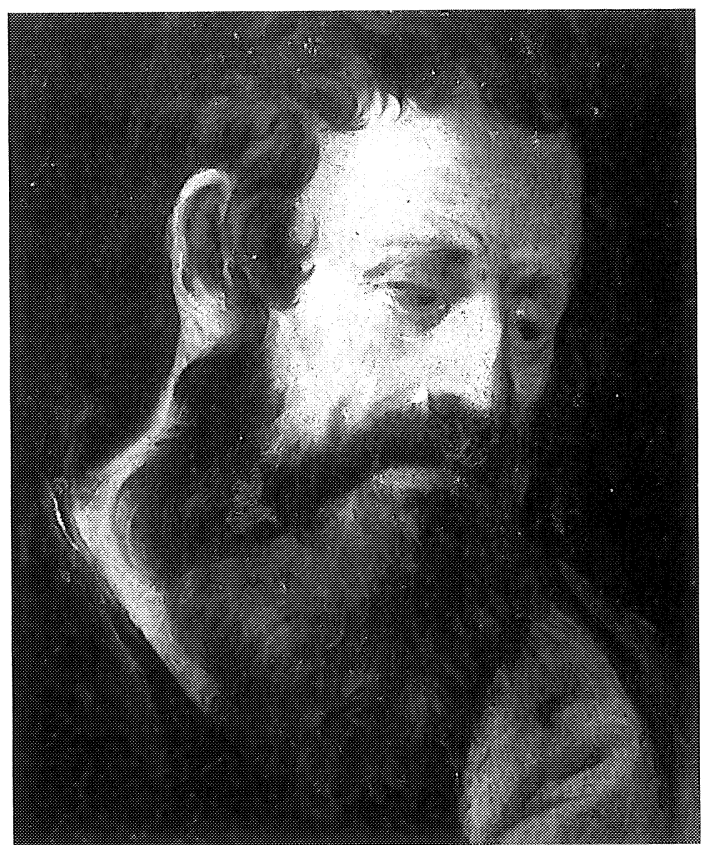

Fig. 12. Herrera "el Viejo», San Juan Evangelista. Córdoba, Museo de Bellas Artes.

Fig. 13. Herrera "el Viejo", San Juan Evangelista, detalle. Córdoba, Museo de Bella Artes.

Fig. 14. Herrera "el Viejo», Santiago el Menor. Córdoba, Museo de Bellas Artes.

Fig. 15. Herrera "el Viejo», Santiago el Menor, detalle. Córdoba, Museo de Bellas Artes. 
17
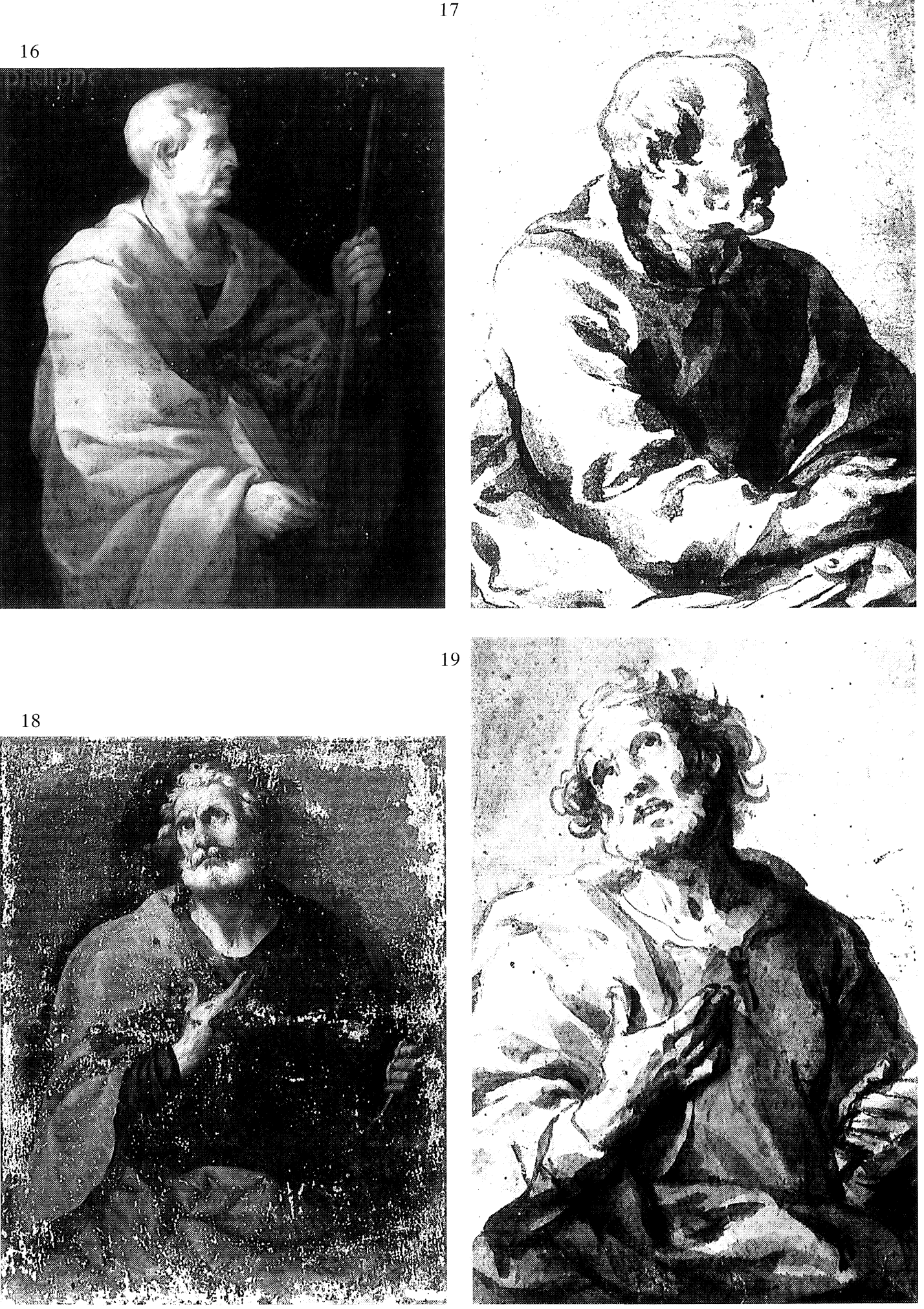

Fig. 16. Herrera "el Viejo", San Felipe. Córdoba, Museo de Bellas Artes.

Fig. 17. Herrera "el Viejo", Apóstol, dibujo. Hamburgo, Kunsthalle.

Fig. 18. Herrera "el Viejo", San Pedro. Córdoba, Museo de Bellas Artes.

Fig. 19. Herrera "el Viejo", Apóstol, dibujo. Hamburgo, Kunsthalle. 


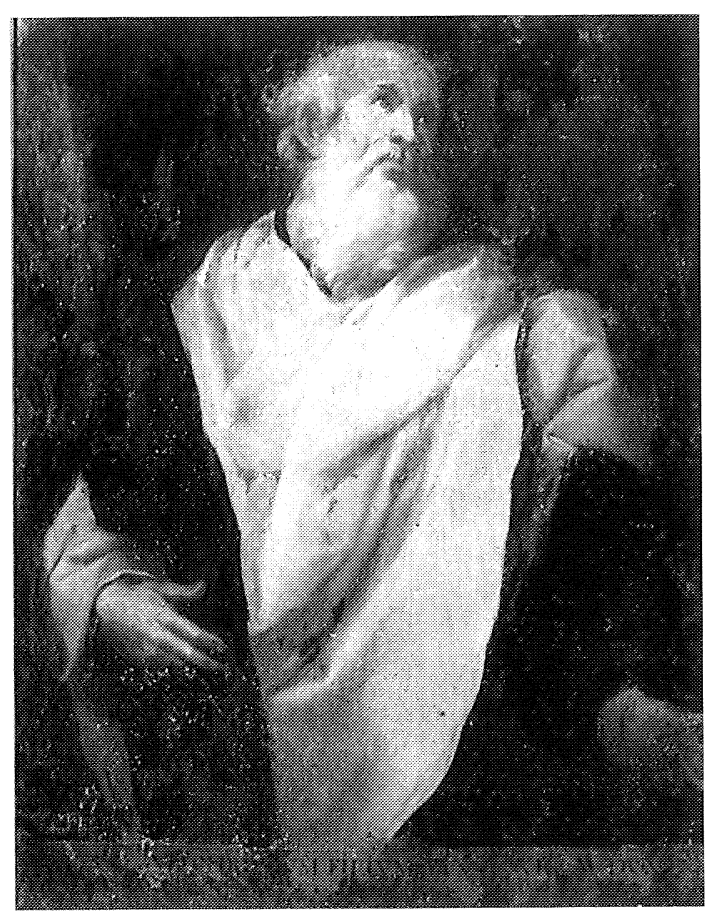

20

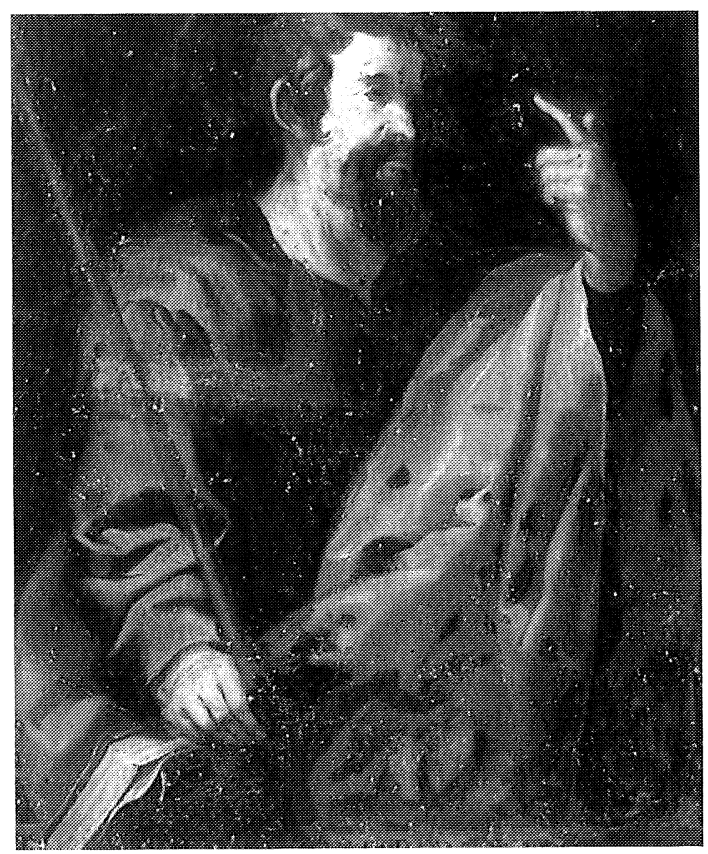

22
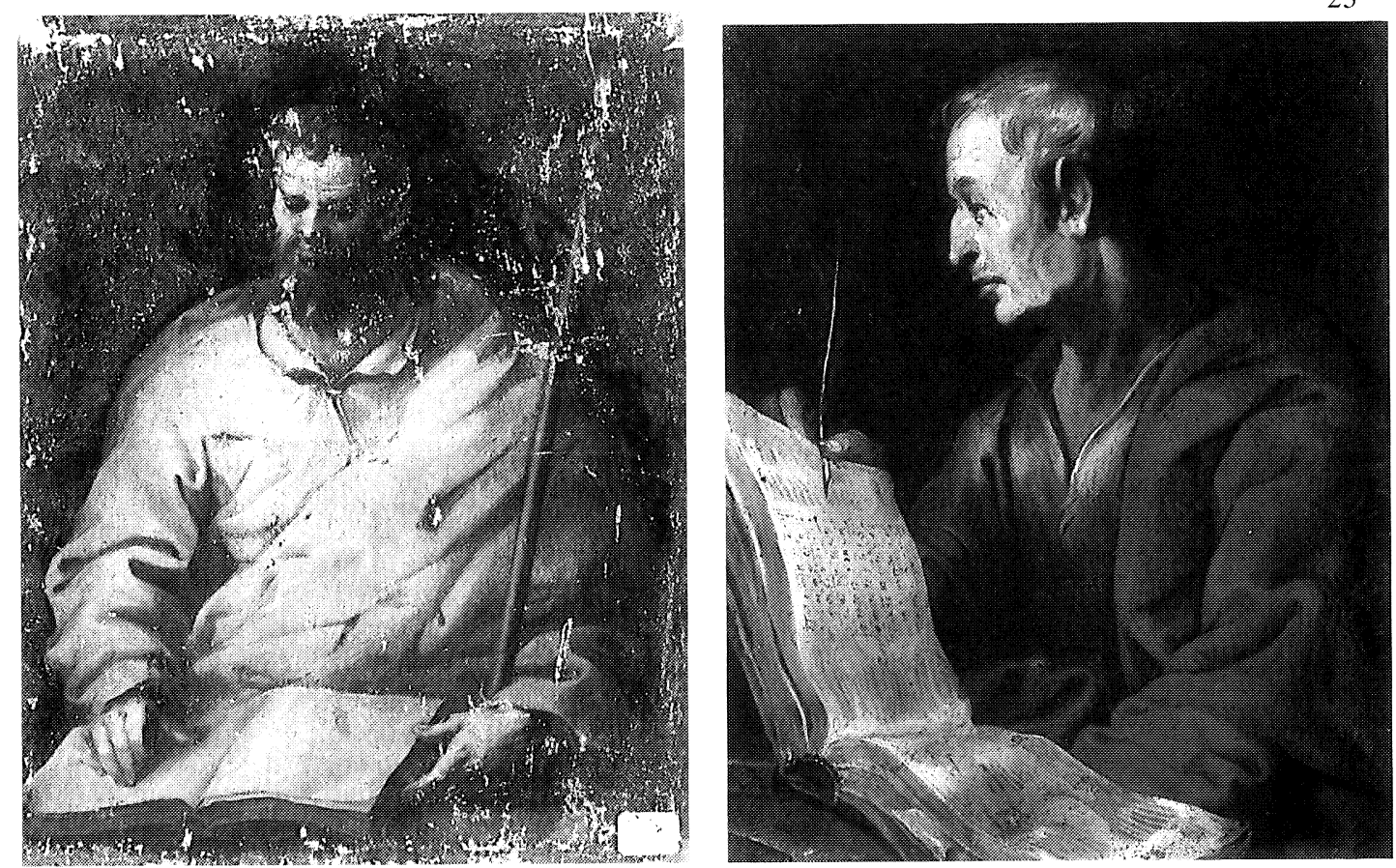

Fig. 20. Herrera «el Viejo», Santiago el Mayor. Córdoba, Museo de Bellas Artes.

Fig. 21. Herrera "el Viejo", Apóstol. Córdoba, Museo de Bellas Artes.

Fig. 22. Herrera "el Viejo", Santo Tomás. Córdoba, Museo de Bellas Artes.

Fig. 23. Herrera «el Viejo", Filosofo. Florencia, Colección Particular. 
nacossi, que se ha considerado Pitágoras, a juzgar por las tablas numéricas que muestra el amplio infolio que sostiene en las manos (Fig. 23).

Visto de perfil, y tratado con la habitual energía en el manejo del pincel, el modelo humano se relaciona muy directamente con uno de los dibujos de Hamburgo ${ }^{18}$. La nariz fuertemente aguileña, la barbilla redonda y prominente, el acusado maxilar y la enorme oreja aproxima estrechamente los dos modelos; aunque en el dibujo parece acentuarse más la edad y la calvicie.

No se trata evidentemente de un dibujo preparatorio, pero muestra sin duda alguna la estrecha relación entre los diversos modelos empleados por Herrera, y su predilección por tipos de muy acusado carácter.

Creemos que esta figura de filósofo, al igual que los Apóstoles ya citados, o ciertas figuras como el Viejo escritor que el Prado tiene depositado en la Universidad de Sevilla ${ }^{19}$ permiten asegurar que Herrera estudió con interés y admiración evidente las obras de Ribera que llegaban a Sevilla, en modo análogo a cuanto hicieron Velázquez, Cano y Zurbarán, interesándose sobre todo por el carácter intenso y la inmediata realidad de los tipos más que por los efectos de contraste tenebrista, aunque no los rehuyese.

El parentesco, incluso temático, con las figuras de filósofos que Ribera pintó para el Duque de Alcalá, que debieron ser conocidas pronto en Sevilla, permiten también suponer una fecha avanzada en la producción de Herrera, sin duda en los comienzos de la década de los cuarenta.

Obra tardía que habrá que situar también en fecha próxima a 1640-45 es una hermosa Inmaculada Concepción con San Joaquín y Santa Ana que, fotografiada en Sevilla en los años treinta cuando se hallaba en el comercio, reapareció en una venta pública en Madrid hace años ${ }^{20}$ y pertenece hoy a un coleccionista madrileño (Fig. 24).

La figura de la Inmaculada, de recogida silueta, que se aproxima a los modelos de Alonso Cano por su perfil fusiforme y el modo de recoger los pliegues de la túnica sobre los pies, la conocíamos ya a través de un dibujo de la Real Academia de San Fernando ${ }^{21}$ que resulta ser preparatorio para esta composición, sin otra variante que tener la cabeza un poco más inclinada que en el lienzo.

Con túnica carmín violáceo y manto azul, la Virgen responde a la iconografía sevillana más característica de los años 20-30; y encuentra su paralelo en otras de Zurbarán, Velázquez y Cano, que serán algunos años anteriores.

Las figuras de los padres, erguidos y monumentales, envueltos en amplias vestiduras de buscada solemnidad, se muestran -en el detalle de su rostro lo mismo que el paisaje de fondo-, de materia más fluida y esponjosa que lo habitual en las obras de las décadas de los 20 y los 30 .

La silueta y los plegados del San Joaquín, se relacionan muy directamente con el dibujo de San Bartolomé del British Museum de Londres, fechado en $1642{ }^{22}$ y el tratamiento de su barba, esponjosa y fluyente, también obliga a pensar en una fecha no lejana del San Pedro arrepentido de la Colección Gómez de Barreda, de hacia 1645-48 e incluso de la Cabeza degollada del Prado, ésta, sin duda, aún más tardía.

La gama de color, con el amarillo encendido del manto de Santa Ana, que llena el lado derecho de la composición, hace evocar la Presentación de la Virgen en el Templo de la Academia de San Fernando, en la que el personaje de la derecha viste un amplio manto de idéntico color, tratado de modo muy semejante y donde aparecen también, en el personaje de la izquierda, tonos

\footnotetext{
18 Angulo-Pérez Sánchez, A Corpus of Spanish Drawings, Vol. III. Sevilla School, 1600 to 1650, Londres, 1985, n. ${ }^{16}$, lám. V. Pérez Sánchez-Navarrete, Sevilla, 1995, n. ${ }^{\circ} 13$, p. 129.

19 Martínez Ripoll, 1978, p. 158, n. ${ }^{\circ}$ P.72, fig. 63.

20 Sothebýs Madrid, 22 Abril 1982, lote n. ${ }^{\circ} 205$. Mide $1,97 \times 1,30$.

21 Angulo-Pérez Sánchez, ob. cit., 1985, n. ${ }^{\circ} 29$, lám. IX.

22 Angulo-Pérez Sánchez, ob. cit., 1985, n.o 3, lám. III.
} 
violáceos idénticos a los de la túnica de esta Inmaculada. Fechable el lienzo de la Academia en los últimos años de la década de los treinta, puede éste perfectamente situarse unos años más tarde, ya en la década de los cuarenta como hemos dicho.

Bien conocidas son las versiones del San José con el Niño del Museo de Bellas Artes de Budapest y del Museo Lázaro Galdiano, fechadas respectivamente en 1645 y en 1648 que han sido a veces tratadas con cierto desdén por considerarlas dulcificadas en exceso ${ }^{23}$. Parece indudable que Herrera quiso atemperar su genio a la sensibilidad más delicada de su tiempo, especialmente en el lienzo de Budapest -cuyo Niño Jesús se diría anunciador de los de Murillo-, hasta haber hecho dudar de su entera autografía, y pensar (Martínez Ripoll) en la posible colaboración de su hijo Francisco, el futuro Herrera el Mozo.

La aparición de un tercer ejemplar de colección particular, de calidad soberbia y factura más enérgica, fechado en 1641, obliga a reconsiderar la cuestión, y a ver, efectivamente, en los hasta ahora conocidos repeticiones con más o menos colaboración del taller, de este prototipo de evidente fuerza expresiva y técnica recia, más acorde con sus obras más significativas de la década de los 30, y como ellas, más rica y densa de color (Fig. 25).

Aún puede añadirse al Catálogo del pintor, otro San José de composición bien diversa, en pie, sosteniendo al Niño en sus brazos, con un amplio fondo de paisaje (Fig. 26). Compareció, correctamente atribuido a Herrera, en una venta pública (Sothebýs-Mónaco, 5-6 diciembre 1991, lote n. ${ }^{\circ}$ 253), con la errónea identificación de San Cristóbal portando a Cristo. A juzgar por la excelente fotografía del Catálogo, se trata de una obra característica de los años centrales de su producción. La figura, solemne con amplios ropajes, enlaza sin dificultad con otras de los años 30-40, y aun posteriores, como los padres de la Virgen en la Inmaculada ya comentada.

Arriesgada resulta la atribución que proponemos a Herrera el Viejo, de un hermoso lienzo con el Bautismo de Cristo, recientemente aparecido en el mercado artístico madrileño ${ }^{24}$ (Fig. 27).

Si fuese suyo, como pensamos, habría de corresponder a un momento muy avanzado de su producción, pues el tratamiento de la materia se hace extraordinariamente fluido y el paisaje parece impregnado ya de cierto tono "moderno» análogo al de Murillo o Iriarte. Pero en la sólida figura de San Juan, en el modo en que su cabello aplastado se ciñe a la oreja derecha, en el modo de modelar el rostro y resolver la nariz con una pincelada de segura y seca precisión e incluso en los plegados abultados y llenos de aristas, a pesar de su tratamiento más blando que en las obras más conocidas y carácterísticas, puede rastrearse, creemos, la peculiar manera del maestro que seguramente en sus años madrileños, tras conocer otras cosas más «nuevas» hubo de dulcificar su estilo y atemperarlo a los tiempos y los gustos de tiempo. Los grandes pies, y el curvo modelado de la pierna derecha del Bautista parecen repetir, todavía, los del Job del Museo de Rouen, cuya masa arbórea parece preanunciar lo que aquí se muestra.

Carecemos de términos de comparación precisos, pero la Cabeza degollada de Santo del Museo del Prado, que fue restaurada en 1993 ofrece una fluencia del color, una manera de modelar con el pincel y un tratamiento del cabello y barba muy semejantes a lo que puede verse en el rostro de Cristo, y, una vez limpia, no cabe duda de que la hermosa cabeza, firmada sin fecha, corresponde a un momento muy distante de las obras sevillanas del pintor ${ }^{25}$.

Un curioso lienzo maltratado de dimensiones $1,33 \times 1,92$, que representa a San Jerónimo, firmado en un papel: «Franco. Herrera/fecit. Año 1650» (Fig. 28), resulta de difícil inserción en la producción conocida del artista; pues el tipo humano no es en modo alguno habitual en su

23 Martínez Ripoll, 1978, n. ${ }^{\circ}$ P.89 y P.91, láms. 81 y 82.

24 Mide 1,18 × 1,01. Lleva restos de una firma en la que se ha querido leer: «... de Cano».

25 Martínez Ripoll (1978, p. 162, n P.83) sitúa la Cabeza degollada hacia 1638-40, fechas a nuestro juicio, absolutamente inadecuadas. 

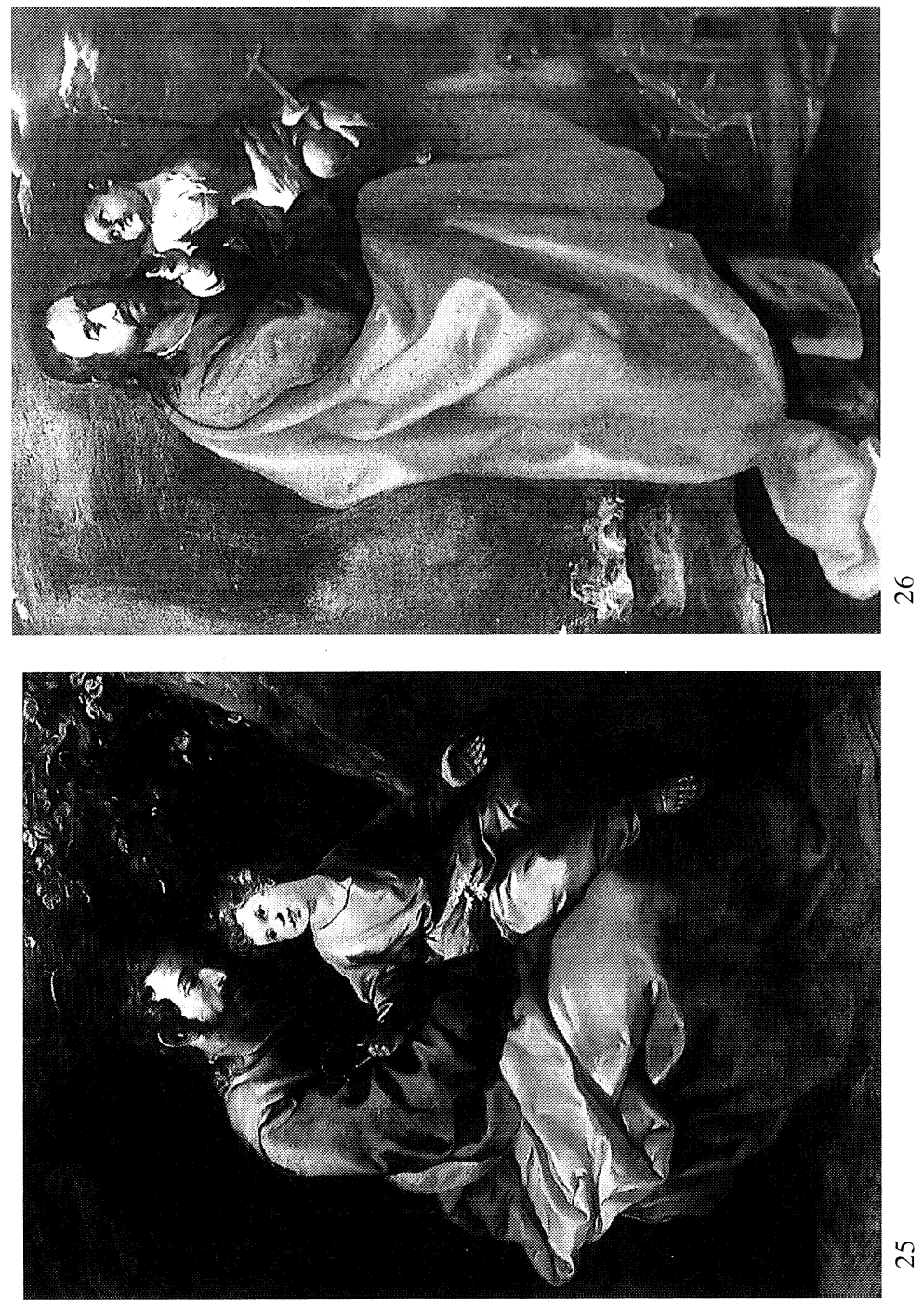

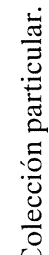
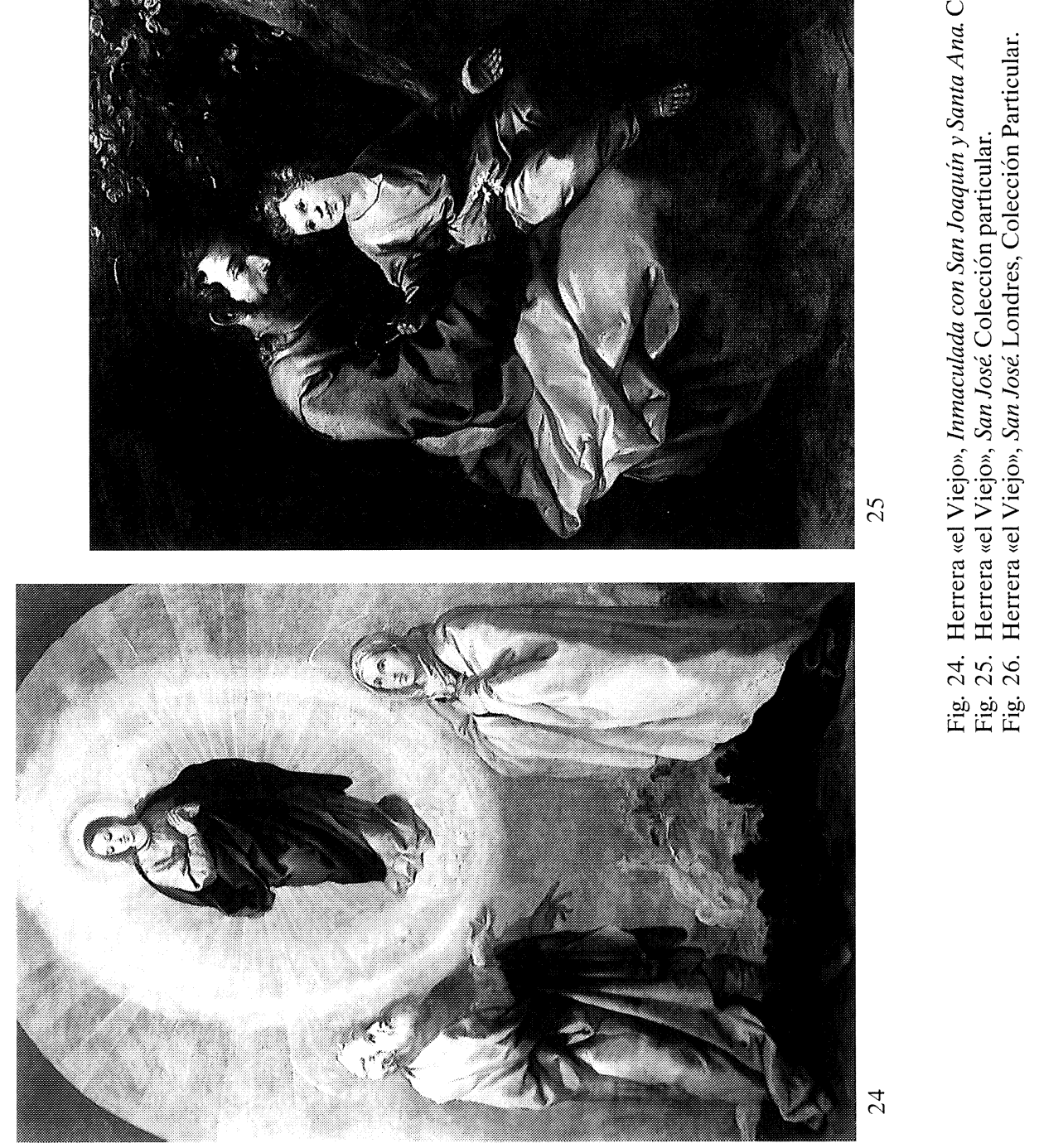

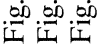


obra conocida y el estado de conservación impide, tanto en la fotografía como en el natural, reconocer las características más firmes de su estilo personal. No obstante, creo que no hay que dudar de la autenticidad de la firma -quizás reforzada- y que aspectos tales como el pie izquierdo, bien visible, la cabeza del león, las raíces que se adivinan al fondo a la izquierda, y la mano que sostiene la calavera, permiten reconocer en el lienzo, desfigurada quizás por viejas restauraciones alteradas, una obra autógrafa del momento tardío que es, desde luego, el que peor conocemos.

Es muy posible que este lienzo sea el que en 1856 poseía don José de Madrazo, en el Catálogo de cuya colección se recoge bajo el número 368 un San Jerónimo en el Desierto de Herrera el Viejo, de dimensiones 2,00 $\times 1,39$, que son, virtualmente las mismas que tiene el presente lienzo. Martínez Ripoll lo recoge entre las obras perdidas con el n. ${ }^{\circ}$ P.p. 14.

Aún es posible que sea el mismo lienzo que el Canónigo sevillano López Cepero tenía en venta en Sevilla, tasado en 2000 reales, se le describe: «San Jerónimo en el desierto, de cuerpo entero, del tamaño natural» bajo el n. ${ }^{\circ} 61{ }^{26}$.

Todavía podemos añadir otra obra, importante y maltratada, que presenta bien legible la firma de: «Franco. Herrera pin... 1650» pero cuyo estilo difiere notablemente de hasta ahora hemos visto. Se trata de una gran Adoración de los Reyes que se conserva en el Seminario de Vitoria ${ }^{27}$. Sorprende en ella, ante todo, el canon esbelto de sus personajes, de cabeza pequeña y rasgos menudos, especialmente en la Virgen, y el modo de resolver los pliegues, con pinceladas deshechas y restregadas, bien diversas del plegado rotundo y monumental de las obras bien documentadas (Fig. 29).

Hay sin embargo en el rostro de los niños -tanto en el Niño Jesús, como en los pajecillos que siguen a los monarcas - una evidente continuidad con sus modelos habituales de rostros anchos y ojos algo juntos, decididamente feos, que se han mantenido a lo largo de toda su producción al representar ángeles niños.

A pasar de la penosa conservación, sucio y con viejos repintes que dificultan su lectura, se advierte una voluntad colorista más rica que en otras obras anteriores, aunque manteniéndose siempre en una unidad tonal de amarillos, rojos y castaños dorados, que no difieren demasiado, salvo en el tratamiento del pincel, de lo que consideramos más característico suyo.

Hay además, una complacencia en los accesorios de naturaleza muerta, en los objetos suntuosos que portan los Reyes y en sus riquísimos atuendos resueltos con pinceladas menudas y efervescentes, que resultan sorprendentes, si se comparan con lo más habitual en sus composiciones mejor conocidas, aunque algo semejante puede verse en la Adoración de los Reyes del Museo de Arte de Cataluña en Barcelona, de muy distinta composición sin embargo, y también en mal estado de conservación (Fig. 31).

Parece incluso que hubiese en su centelleo y en el movimiento crispado del pincel, algo que anunciase el fogoso movimiento de Valdés Leal, que en esos años iniciaba su estilo más personal. Piénsese que las pinturas de éste en Santa Clara de Carmona son de 1653 y ya hay en ellas mucho de lo que será más característico en su estilo maduro.

Cabe pensarse, si efectivamente este lienzo es de Herrera tal como su firma parece asegurar, que el viejo maestro ha permanecido atento a las novedades del momento y ha visto obras de los artistas de la generación más joven -tanto en Sevilla como en Madrid-y ha intentado incorporarlas a su propia producción, para no permanecer demasiado al margen de la evolución del gusto.

\footnotetext{
26 Martínez Ripoll, 1978, p. 213, n. ${ }^{\circ}$ P.p. 143.

27 Agradecemos a D. Jesús M. ${ }^{a}$ González de Zárate, la indicación de su existencia y las gestiones para obtener fotografías del cuadro. El lienzo ingreso en el Seminario por donación y lleva, pintados en blanco, los nombres de los donantes D. Pedro Rubiñez y D. Francisco Moriola. La grafía de la firma no está lejos de la que muestra el San Jerónimo antes estudiado.

28 Martínez Ripoll, 1978, n. ${ }^{\circ}$ 68, fig. 58.
} 
El tipo humano de la Virgen con sus menudos rasgos y el tono acumulativo de la composición, no deja también de recordar obras napolitanas del tipo del Maestro del Anuncio a los Pastores, que bien pudieran haber sido conocidas por Herrera en la propia Sevilla o en Madrid, si es que el lienzo se pintó ya en la Corte.

A la luz de cuanto se da a conocer ahora y tras revisar atentamente la producción entera del pintor, vale la pena hacer algunas consideraciones sobre la evolución de su personalidad artística y la asimilación de cuanto fue llegando a su conocimiento.

Aceptada generalmente una fecha en torno a 1590 para su nacimiento, es evidente que sus primeros contactos con el mundo artístico en casa de su padre, iluminador y grabador, tuvieron que tener lugar hacia 1600, cuando Pacheco y Roelas iniciaban su madurez pero es preciso tener en cuenta también la presencia de un artista de la generación anterior, Pablo de Céspedes, muerto en 1608 que, aunque residente en Córdoba, mantuvo siempre contacto con Sevilla y con su amigo Pacheco y estuvo aureolado con el prestigio de su estancia romana.

Se ha citado a Pedro de Campaña ${ }^{29}$ como competente de su estilo, y modelo en sus años de aprendizaje, de modo no enteramente convincente. El extremado patetismo del maestro flamenco, sus proporciones alargadísimas y su gusto por la verticalidad no aparecen en absoluto en la obra de Herrera, que prefiere unas formas corpulentas y unos volúmenes ampulosos que entroncan mejor con el romanismo de Céspedes.

La Virgen con los huérfanos del Palacio Arzobispal de Sevilla -fechable hacia 1610-14, y hasta hoy, su primera obra conocida - con su rotunda apariencia y los querubines de rostros anchos y feos, derivan claramente en su composición de la Virgen Inmaculada con ángeles del Museo de Córdoba, procedente del Convento de Capuchinos de aquella ciudad, obra atribuida tradicionalmente a Céspedes, fechable hacia $1580^{30}$. Incluso los ángeles que acompañan a la Inmaculada de Herrera del Museo de Estocolmo, obra mucho más tardía, siguen exhibiendo sus generosas anatomías aun miguelangelescas, bien entroncables con Céspedes y sus modelos.

Herrera debió conocer bien las obras de Céspedes y no solo en Sevilla sino también en Córdoba, para donde trabajó en su juventud. Recuérdese que en 1617 había hecho la traza para un retablo de la catedral de Córdoba, que había de ejecutar el arquitecto y escultor Luis Ortiz de Vargas ${ }^{31}$.

Pero el romanismo de las formas y de los volúmenes se muestra, como bien se ha visto, a través de la pincelada suelta y el colorido cálido aprendido en Roelas, aunque -y esa es la diferencia fundamental entre ambos maestros- sin renunciar a una definición precisa de las formas, basada en el dibujo severo y en la exacta delimitación de los contornos.

Su gusto por las gamas de colores reducidos y el uso de una pincelada larga y modeladora, distinta de la más grumosa y esponjosa de Roelas, permite diferenciarlos con absoluta precisión, aunque en otro tiempo se confundieran sus obras con atribuciones gratuitas.

Esa fusión de preciso dibujo y cálido colorido veneciano, no era nueva en Sevilla, pues había habido ocasión de apreciarla en algunas obras importadas, como el famoso Juicio Final de Martin de Vos, o el Tríptico del Calvario del Hospital de las Bubas, de Francken, ambos hoy en el Museo sevillano.

Los desnudos del Juicio Final de San Bernardo, pintados por Herrera entre 1622 y 1629, con su tersura casi escultórica y su desmesura muscular proceden, como supieron ver Thacher y Soria, de la famosa tabla de Martin de Vos, hoy en el Museo. A su lado los de Vargas y los de Pacheco resultan de una frialdad yerta.

29 Martínez Ripoll, 1978, p. 17.

30 A pesar de la tradicional atribución a Céspedes, que consideramos suficientemente convincente, A. Garrido ( $\mathrm{Pa}$ blo de Céspedes (1538-1608). Su obra pictórica en Córdoba». Homenaje al Prof. Jesús Hernández Perera, 1994, pp. 363370); ha dudado recientemente de ella, pero en cualquier caso la sitúa bajo la influencia del racionero y hacia 1580.

31 Martínez Ripoll, 1978, p. 19. 
Herrera advirtió ya en el modelo flamenco "venecianizado", la fuerte carga de realidad y sensualidad que el tiempo, requería, y al hacerla suya, avanzó señaladamente hacia la plenitud barroca en un mundo absolutamente personal.

Pero hay también un contacto, evidente a nuestro juicio, que no ha sido señalado y que es bien significativo.

Sabemos documentalmente de relaciones personales con Alonso Cano, que nacido en 1601; sería unos diez o doce años más joven que Herrera. En 1633 nuestro artista da carta de pago a favor de Cano por el traspaso de unas casas ${ }^{32}$. Se hallaban pues en contacto y habían de conocer recíprocamente sus obras. La sensibilidad de Cano es bien diversa de la de Herrera y se manifiesta siempre con un tono de delicadeza y sobriedad elegante, bien distinta de la áspera condición de nuestro artista. Pero hay algunos elementos de tipo iconográfico que solemos considerar característicos de Cano, que aparecen en algunas obras de Herrera, subrayando un evidente contacto.

La silueta fusiforme de las Inmaculadas, es sin duda el más llamativo. Si, como creemos, la Inmaculada que se atribuyó a Velázquez hace unos años ${ }^{33}$ es obra de Cano, fechable hacia 1620-22, resulta significativa la presencia en el gran lienzo de San Francisco Javier de la Universidad de Sevilla de una imagencita de la Inmaculada que repite su silueta con el característico estrangularse de los paños a la altura de los tobillos, para abrirse luego a modo de amplia peana.

Igualmente acusado es el paralelismo, ya señalado más arriba, de la Inmaculada con San Joaquín y Santa Ana y su dibujo preparatorio, de tono tan directamente canesco, así como la utilización de modelos femeninos de proporciones, tocado y carácter estrechamente vinculados a los de Cano en los dos dibujos de las Marías del Museo del Prado ${ }^{34}$.

No estando fechadas con precisión las obras de Herrera en las que se señala esa influencia o contacto, no se puede asegurar con precisión que el artista de mayor edad se dejase fascinar por la elegancia del más joven. El lienzo de la colección madrileña con la Inmaculada y sus padres es sin duda, como hemos dicho, obra muy tardía, pero el San Francisco Javier es, desde luego, obra de la década de los veinte, contemporánea estricta de la Inmaculada del joven Cano.

Creemos que puede ser útil añadir algunas notas a ciertas obras dadas por perdidas en los repertorios de Thacher (1937) y de Martínez Ripoll (1978) de las cuales hemos podido añadir algunas precisiones o hipótesis nuevas, que pueden servir a quienes se ocupen de Herrera en el futuro.

La Venida del Espíritu Santo que fue altar en el Convento de San José y compañera de la $\mathrm{Fa}$ milia de la Virgen hoy en Barcelona, se considera desaparecida, y efectivamente nada sabemos hoy de su paradero, pero debió pasar por la colección del Canónigo López Cepero. En su Catálogo de 1860 se recoge bajo el n. ${ }^{\circ} 545$, una Venida del Espíritu Santo, firmada, de dimensiones 7 pies 5 pulgadas $\times 9$ pies 4 pulgadas, que equivalen a metros $2,08 \times 2,62$, dimensiones muy próximas a las originales del lienzo de Barcelona, que está cortado 35 .

Debe advertirse que las dimensiones del Catálogo López Cepero dan primero la anchura y después la altura, al revés de lo que es habitual.

Martínez Ripoll ${ }^{36}$ recoge de Ponz la noticia de que en el Palacio Episcopal de Córdoba había obras de Herrera el Viejo, entre las de otros artistas; procedentes todas de la colección del obispo Caballero y Góngora, que había sido Arzobispo de Santa Fe y Virrey de Colombia.

De una, al menos, tenemos descripción: Una media figura de San Pedro Penitente "perfectamente circular", se vendió en la almoneda del obispo y la adquirió en 320 reales D. José Rugania ${ }^{37}$.

\footnotetext{
32 Martínez Ripoll, 1978, pp. 33 y 262.

33 Sothebýs Londres, 6 julio 1994, lote 64.

34 Angulo-Pérez Sánchez, 1985, n. ${ }^{\circ} 31$ y 32, lám. X y Pérez Sánchez-Navarrete, 1995, n. 34 y 35.

35 Las dimensiones del lienzo de Barcelona son en la actualidad 1,94 × 1,73.

36 Martínez Ripoll, 1978, p. 190, n. ${ }^{\circ}$ P.p.2.

37 Arancha Doncel, 1986.
} 
El Cristo con la Cruz a cuestas que Mayer señalaba en la Universidad de Madrid, y que ni Thacher ni Martínez Ripoll ${ }^{38}$, lograron localizar, pasó de la Universidad al Prado y no es obra de Herrera sino pieza bastante más tardía y probablemente madrileña.

La Incredulidad de Santo Tomás que fue de la Colección Standish, reapareció en 1910, en una venta de Christiés (19 de febrero), siendo adjudicada en 7 libras 17 chelines ${ }^{39}$. Nada se sabe de ella con posterioridad.

Sin que pueda afirmarse de modo rotundo, pues resulta demasiado distante de las obras absolutamente seguras de su mano, creo que debe apuntarse la hipótesis de que el gran lienzo de las Bodas de Canaá que guarda el Museo de Castres, considerándolo obra de escuela madrileña ${ }^{40}$, sea el lienzo que procedente del Palacio Arzobispal sevillano perteneció a la colección Soult y fue vendido en 1852 por 2.400 francos ${ }^{41}$ (Fig. 30 ). Sus dimensiones $(2,43 \times 5,65)$ son bastante mayores que las recogidas en el Catálogo de la venta Soult $(2,44 \times 4,12)$ pero la descripción, aunque un tanto genérica, conviene a la letra con lo que el lienzo muestra: «El banquete se desarrolla en una sala suntuosamente decorada. El momento elegido por el pintor es aquel en que la Virgen advierte a su hijo que el vino comienza a faltar. La respuesta de Cristo preocupa y tiene atentos a todos los invitados. Cerca de un aparador provisto de bellos jarrones se levanta una tarima ocupada por músicos».

El lienzo presenta señales de haber sido doblado, y debe recordarse que en la Colección Soult se le consideraba - como los otros lienzos compañeros- obra de Herrera el Mozo, a pesar de que Ceán Bermúdez lo había citado como del Viejo. En su estado actual es difícil juzgar, pero es muy posible que la atribución de Ceán no fuese acertada. Algunos rostros recuerdan más a Sebastián de Llanos Valdés, que debió ser discípulo de Herrera.

Muy distinto es el caso de un hermosísimo lienzo, de colección particular madrileña y dimensiones 1,83 $\times 2,00$, representando a San Antonio predicando a los peces que ha de identificarse con el «lienzo grande» de ese asunto que hubo en el Claustro del Convento franciscano de San Antonio de Sevilla 42 (Figs. 31, 32 y 33). No es, evidentemente, obra de segura atribución, pues algo hay en ella diverso a lo más habitual, pero la energía de los rostros, el amplio plegado de los hábitos y la braveza de los peces, que parecen pintados por alguien habituado a la pintura de naturaleza muerta - como Herrera fue, aunque no hayamos conservado ninguna de las muchas que debió pintar-, permiten, al menos, sostener la atribución a modo de hipótesis. Es preciso, además, tener en cuenta el mal estado de conservación de la tela, que ha sufrido limpiezas excesivas y ha perdido mucho de su epidermis. Si fuese efectivamente obra de Herrera, se resolvería el problema de su atribución, que ya se planteó en 1985 en ocasión de su exhibición en la exposición Carreño-Rizzi-Herrera y la pintura madrileña de su tiempo ${ }^{43}$, donde se le fechaba como anónimo «hacia 1630-40 en la tradición de los artistas del primer tercio de siglo», pero en la órbita madrileña. Quizás al emplazarla en el ámbito sevillano encuentre, por fin, su lugar.

Debe subrayarse además, una curiosa circunstancia. En la Colección de los Hermanos Bravo, donde estuvo el lienzo del Convento de San Antonio al menos hasta 1844, se atribuía a Alonso Cano, aunque indicando que se consideraba también de Herrera el Viejo. Sorprendentemente, la proximidad entre ambos artistas, que descubrimos en algunas obras seguras, habría sido ya intuida ante esta obra enigmática.

La descripción que del lienzo se da en la Memoria de la colección de D. Antonio Bravo

\footnotetext{
38 Thacher, 1937, p. 375.-Martínez Ripoll, 1978, p. 191, n. ${ }^{\circ}$ P.p.6.

39 Martínez Ripoll, 1978, p. 217, n. ${ }^{\circ}$ P.p.185.-La venta citada se recoge en el Art Prices Current, 1909-1910. p. 88, n. ${ }^{\circ} 115$.

40 Musée Goya. Petit Album des Collections, Castres, 1989, p. 22, n. 37.

41 Martínez Ripoll, 1978, p. 221, n. ${ }^{\circ}$ P.p.212.

42 Martínez Ripoll, 1978, p. 193, n. ${ }^{\circ}$ P.p.22.

43 A. B. Pérez Sánchez, Carreño, Rizzi, Herrera, Madrid, 1986, p. 352, n. 172.
} 


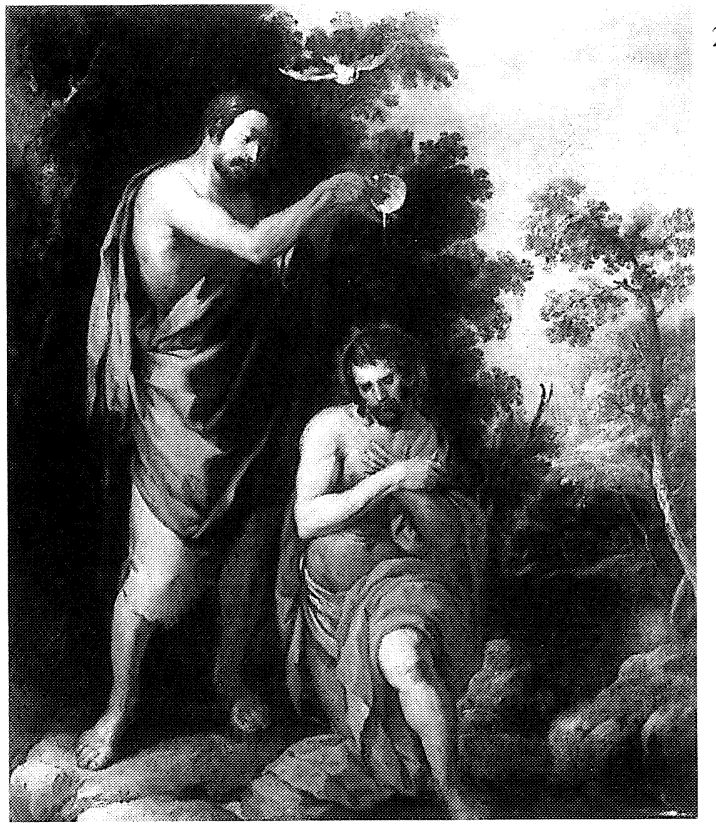

28
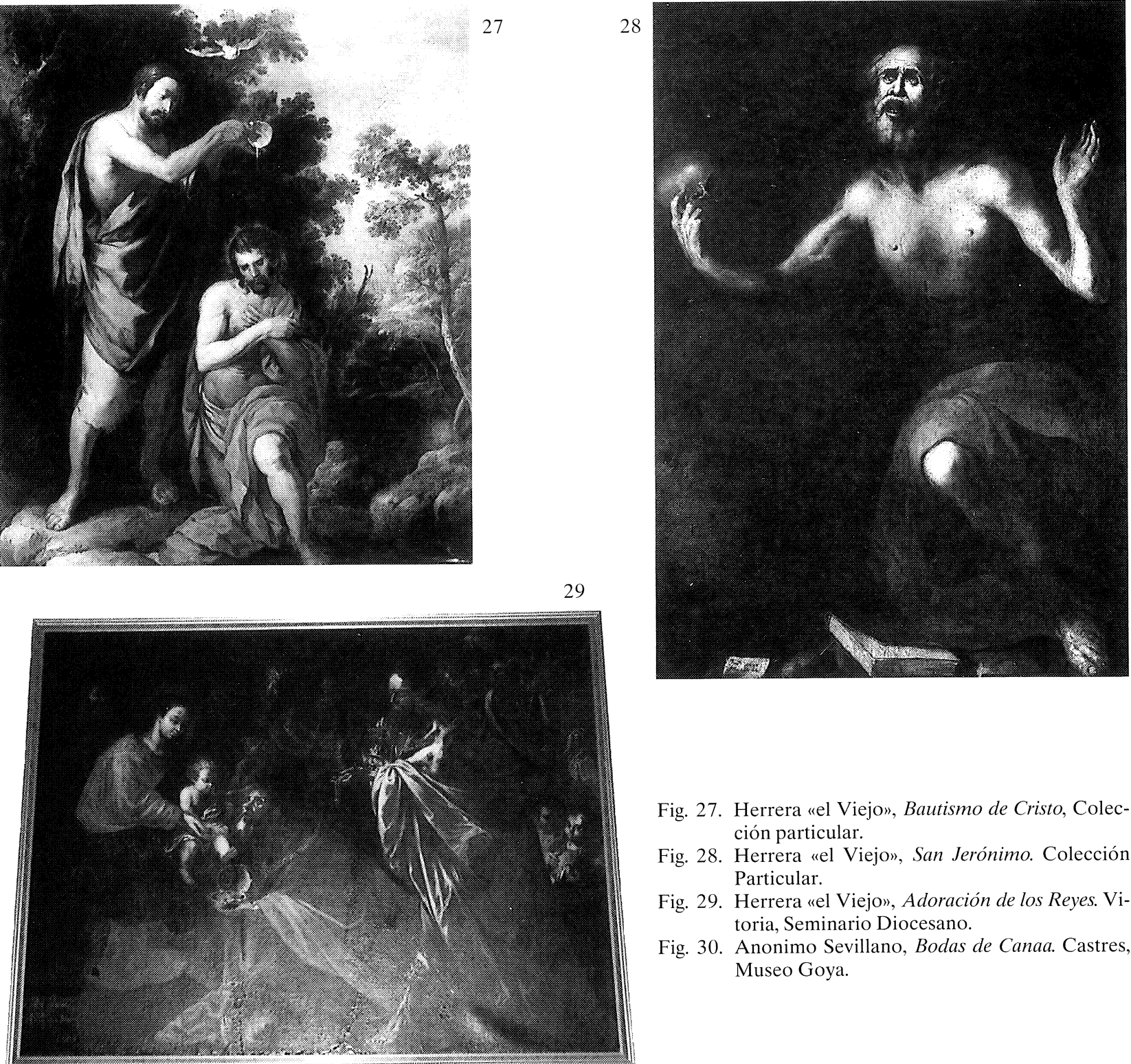

Fig. 27. Herrera «el Viejo», Bautismo de Cristo, Colección particular.

Fig. 28. Herrera «el Viejo», San Jerónimo. Colección Particular.

Fig. 29. Herrera "el Viejo", Adoración de los Reyes. Vitoria, Seminario Diocesano.

Fig. 30. Anonimo Sevillano, Bodas de Canaa. Castres, Museo Goya.

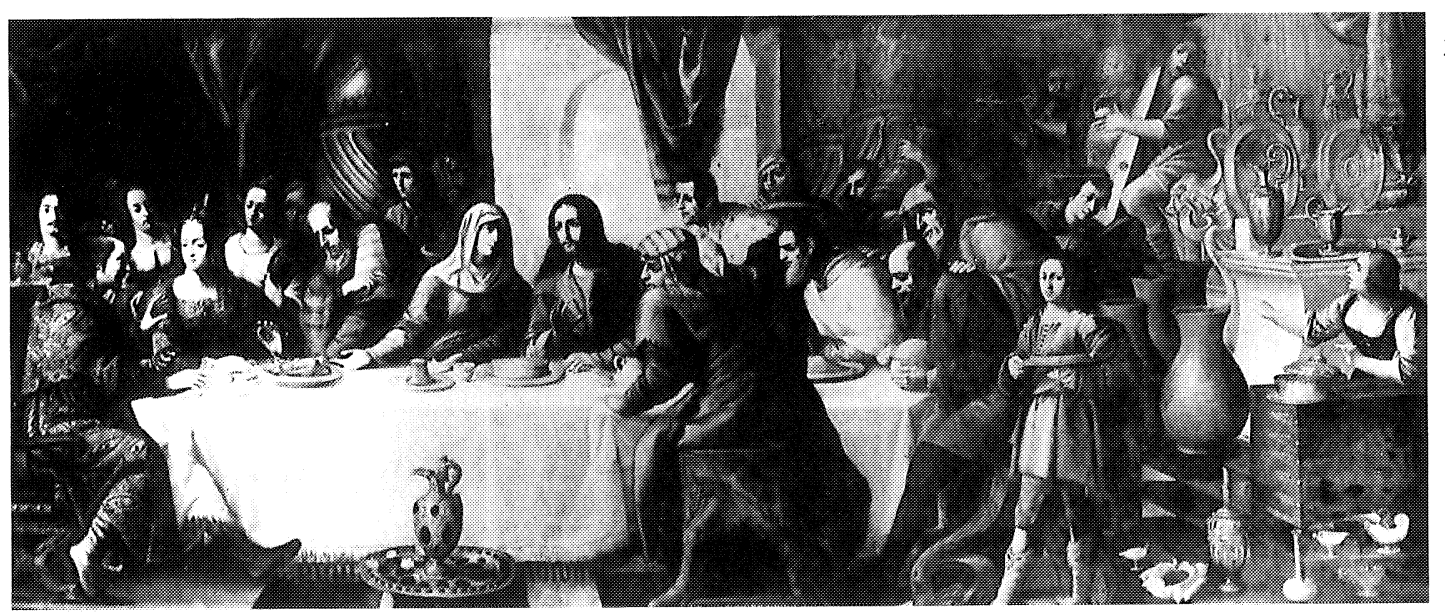



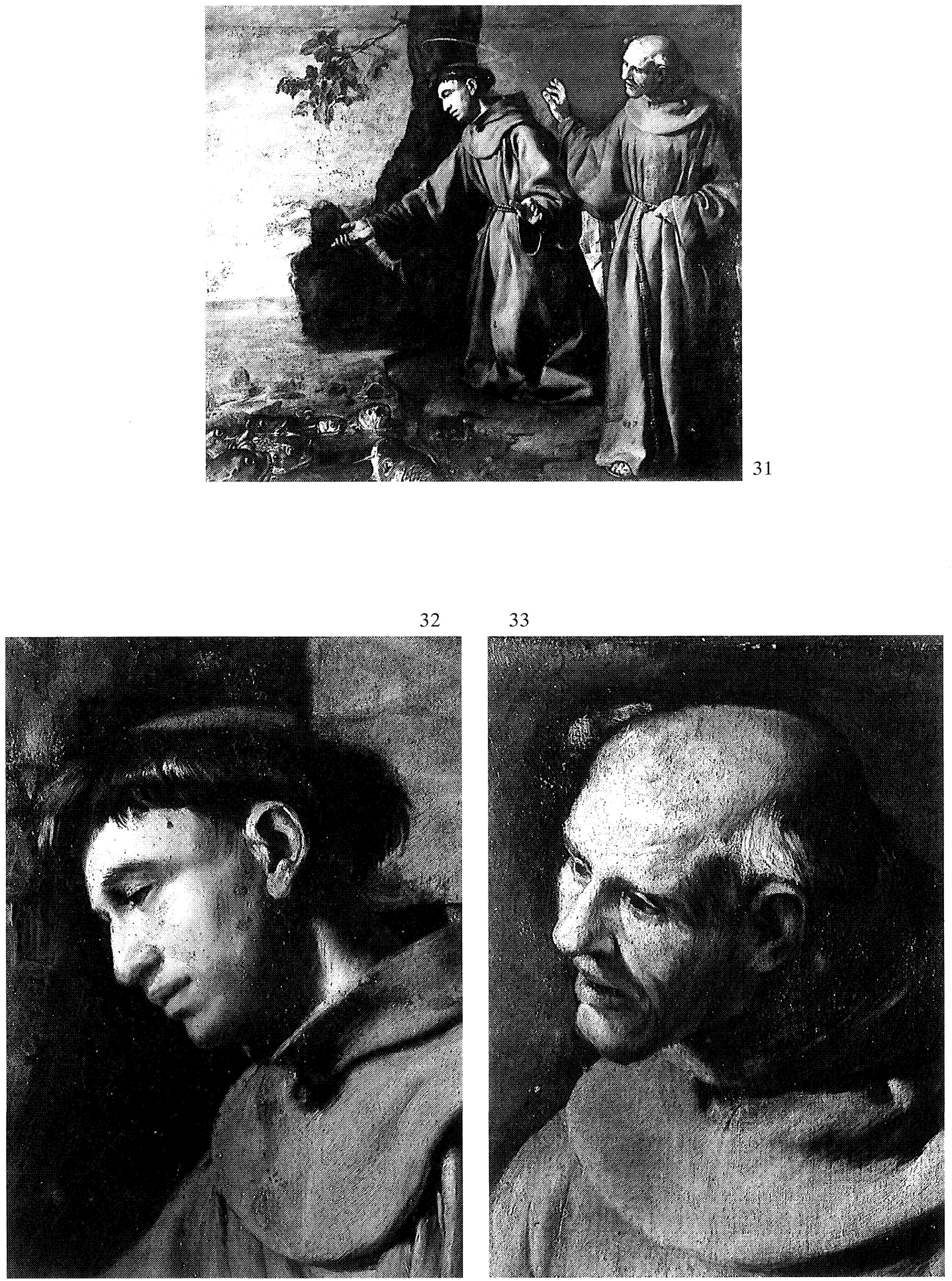

Fig. 31. Herrera "el Viejo", San Antonio predicando a los peces. Madrid, Colección particular. Fig. 32. Herrera "el Viejo", detalle de la figura 31.

Fig. 33. Herrera «el Viejon, detalle de la figura 31 
en 1837, no deja lugar a dudas respecto a la identificación: «Incado el Santo de rodillas, predica a los peces en las orillas del mar de Padua y salen con afán a escucharlo, cosa que no habían querido hacer los habitantes de la ciudad. Un lego que le acompaña está detrás sorprendido. Por entre las dos personas se ve una parte de la población y delante hay un árbol y gran porción de celajes».

Por último, y a manera de apéndice para completar la lista de obras perdidas o no identificadas que ofrecieron Thacher y Martínez Ripoll, incluimos a continuación una sumaria relación de obras atribuidas a Herrera, hoy en paradero desconocido, no recogidas por ellos. Es posible que algunas de ellas no sean de su mano, pero creo útil señalarlas para una posible localización. Algunas indicaciones proceden de las anotaciones manuscritas, extraordinariamente ricas en su telegráfica redacción, que realizó $\mathrm{D}$. Diego Angulo a lo largo de su vida.

La ordenación, para más fácil y cómoda consulta, se ha hecho atendiendo a la iconografía.

\section{Asuntos Evangélicos y Marianos}

- La Virgen y El Salvador. Dos lienzos de $21 / 4 \times 11 / 3$ varas. Inventariados en el Alcázar de Sevilla en 1810 con el número 463 (Gómez Ymaz, Inventario, 1896, p. 90).

- Virgen con el Niño. Sevilla. Merced Calzada (Ponz, Ed. Aguilar, 1947, p. 790).

- Circuncisión. Madrid, San Manuel y San Benito. 1,87 × 2,40. Visto en la Guerra Civil por D. Diego Angulo, que lo anotó corno obra de un discípulo o influido por él (Incautación, 19.100). Hoy no se halla en la iglesia.

- Adoración de los Reyes. Según Carderera (Apud. Viñaza, Adiciones III, 110) lo poseía en Madrid Jovellanos y un lienzo de Juan Moreno, firmado en 1636, copiaba fielmente el manto de uno de los Reyes de este lienzo.

- Cristo entre los Doctores. Se expuso en la exposición de Manchester de 1857 (n. ${ }^{\circ}$ 9651). Pertenecía a Edward Stephen.

- Transfiguración. París. Colección Pereire en 1868 (Feliure, Catalogue de Tableaux, 1868, p. 9 , n. ${ }^{\circ} 351$.

Santos

- San Francisco penitente. Barcelona. Conde de Güell 1,35 × 0,95. Visto por D. Diego Angulo en la Guerra Civil. Le pareció indudable suyo.

- Tránsito de San Francisco de Paula. Vendido en Londres en 1827 en 5 libras. Era de Sir C. Cockerell y lo compró Peacock.

- San Jerónimo penitente. Sevilla. López Cepero. Tenía, de dimensiones, 1 pie 10 pulgadas $\times 1$ pie 3 pulgadas. De cuerpo entero. Se le llama «Boceto». Catálogo de la Galería López Cepero, 1860, p. 512, n. $^{\circ} 649$.

- Retablo de San Hermenegildo. Sevilla. Ermita de San Hermenegildo. Llevaba varias pinturas (Ponz, Ed. Aguilar, 1947, p. 799).

- San Pablo. París. Conde de Rayneval, 1938. Paillet, Notice des Tableaux, p. 14, n. 48.

- Santiago el Mayor $(42 \times 131 / 2$ pulgadas = 1,07 × 0,34). Vendido el 18-19 de Abril de 1934 en las Andersson Galleries de Londres en 300 libras. Art Prices Current, 1933-34, p. 137, n. ${ }^{\circ} 4185$.

- Apóstoles. Sevilla. San Agustín. Según Ponz, algunos los creían de Varela (Ponz, Ed. Aguilar, 1947, p. 798). 
Varios

- Cabeza de monje. Londres. Standish, 1853. Se vendió a Lamert en 2 libras 2 chelines Catálogo Standish, p. 24. Figura en nota manuscrita en el ejemplar del Museo del Prado, bajo el n. ${ }^{\circ}$ 247.

- Viejo con barba blanca. París. Pereire, 1868. Sólo la cabeza. Feliure, Catalogue de Tableaux, p. 10, n. $^{\circ} 36$.

- Retrato de hombre. París. Venta Paul Delaroff. 27-lV-1914, n. ${ }^{\circ} 18$. Medía 49 1/2 × 39 1/2= $1,26 \times 1,00$.

- Cuadros sin precisar en la Capilla de San Lucas de la iglesia sevillana de San Andrés Ceán, 1800 II, p. 277. 